NBER WORKING PAPER SERIES

\title{
"I STILL HAVEN'T FOUND WHAT I'M LOOKING FOR": EVIDENCE OF DIRECTED SEARCH FROM A FIELD EXPERIMENT
}

\author{
Haoran $\mathrm{He}$ \\ David Neumark \\ Qian Weng \\ Working Paper 28660 \\ http://www.nber.org/papers/w28660 \\ NATIONAL BUREAU OF ECONOMIC RESEARCH \\ 1050 Massachusetts Avenue \\ Cambridge, MA 02138 \\ April 2021, Revised January 2022
}

With apologies to U2. We owe a huge thanks to the job board on which we ran our experiment. We are grateful for helpful comments from Xiaoming Cai, Chao He, Daniel Houser, Binglin Gong, Zhiyun Li, David Ong, Xiangquan Zeng, participants at the 2020 ESA Global Online Conference, the 2020 Beijing Normal University Conference on Experimental Economics, the 2020 International Symposium on Labor Economics, seminar participants at Harbin Institute of Technology at Shenzhen, Jinan University, Peking University, Shandong University, Wuhan University, and Xiamen University, and anonymous referees. We thank Shiwen Chen, Yiqiang Guo, Wanyu Jiang, Kelin Lu, Yue Yin, Zhuo Zhang, and especially Shuqing Luo for research assistance. Financial support from the Ministry of Education of China (Project No. 21YJA790059), the National Natural Science Foundation of China (Project Nos. 71973016 \& 72131003) and the National Program for Special Support of Top-notch Young Professionals is gratefully acknowledged. The experiment described in this paper was approved by the Institutional Review Board of Beijing Normal University Business School (BNU-BS-IRB 2021-026). All authors made equal contributions. Any remaining errors are our own. The views expressed herein are those of the authors and do not necessarily reflect the views of the National Bureau of Economic Research.

NBER working papers are circulated for discussion and comment purposes. They have not been peer-reviewed or been subject to the review by the NBER Board of Directors that accompanies official NBER publications.

(C) 2021 by Haoran He, David Neumark, and Qian Weng. All rights reserved. Short sections of text, not to exceed two paragraphs, may be quoted without explicit permission provided that full credit, including $\odot$ notice, is given to the source. 
“I Still Haven't Found What I'm Looking For": Evidence of Directed Search from a Field Experiment

Haoran He, David Neumark, and Qian Weng

NBER Working Paper No. 28660

April 2021, Revised January 2022

JEL No. E24,J64

\begin{abstract}
We explore the impact of wage offers on job applications, testing implications of the directed search model and trying to distinguish it from random search. We use a field experiment conducted on a Chinese job board, with real jobs for which we randomly varied the wage offers across three ranges. We find that higher wage offers raise application rates overall, which is consistent with directed search but can also arise with random search. We also find that higher wage offers raise application rates for job seekers with wage offers above reservation wages, and that - among the latter - the increase in application rates is stronger for those with higher reservation wages. The latter two types of evidence are consistent with directed search but not random search. Hence, our evidence lends support to directed search models.
\end{abstract}

Haoran $\mathrm{He}$

Beijing Normal University

No 19, Xinjiekouwai St.

Haidian District

100875 Beiing

China

haoran.he@bnu.edu.cn

David Neumark

Department of Economics

University of California, Irvine

3151 Social Science Plaza

Irvine, CA 92697

and NBER

dneumark@uci.edu
Qian Weng

Renmin University of China

No. 59 Zhongguancun Street

Haidian District

Beijing 100872

China

qian.weng@ruc.edu.cn 


\section{Introduction}

Existing models of the labor market in the search and matching literature often describe a specific way in which workers search for jobs and employers attract workers, i.e., either random search or directed search. Random search models in the Diamond-Mortensen-Pissarides tradition assume that job seekers and employers meet exogenously and at random (e.g., Diamond, 1982; Mortensen, 1982, 1986; Pissarides, 1985). Whether a meeting results in a hire, and at what wage (and/or other terms of trade), is endogenously determined by post-meeting bargaining. As a consequence, changing the wage (and/or other terms of trade) has no influence on attracting workers to jobs. ${ }^{1}$ In contrast, models of directed search (also known as competitive search) assume that agents target their search towards particular counterparts based on the terms posted, and therefore these terms, such as higher wages, influence who meets whom (e.g., Peters, 1984, 1991; Hosios, 1990; Montgomery, 1991; Moen, 1997; Menzio et al., 2016; see Wright et al., 2019 for a review). ${ }^{2}$ The nearly mutually exclusive assumptions of these two types of models lead to different predictions for market efficiency and the effectiveness of certain labor market policies. ${ }^{3}$

${ }^{1}$ There is another class of random search models that assume that job seekers randomly search employers for a job that posts a wage. This class of models has been used extensively in understanding wage dispersion, i.e., how job seekers with identical productivity can be paid different wages, with Burdett-Mortensen (1998) as the most prominent example.

${ }^{2}$ While random search models with posting also predict that higher wages attract more job seekers, they differ from the direct search models in that labor market tightness is not a determinant of the job arrival rate, i.e., the tradeoff between higher wage offers and the lower probability of getting a job is not considered by job seekers.

${ }^{3}$ Random search in general yields inefficient equilibrium trading prices in the Diamond-MortensenPissarides tradition, unless the vacancy-elasticity of the matching function equals the employer's bargaining power (Hosios, 1990). In contrast, the efficiency of directed search equilibrium depends on specific model assumptions, such as the number of (sub)markets workers can search in, whether it is onthe-job search, whether agents can enter the market, etc. (See Wright et al., 2019). For implications for policy effects, see, e.g., Flinn (2006) on the minimum wage; Acemoglu and Shimer (2000) and Braun et al. (2016) on unemployment insurance; and Acemoglu (1997) and Moen and Rosén (2004) on training subsidies. 
Researchers tend to choose random or directed search for analytical convenience (although theoretical implications can differ), rather than based on the best characterization of job seekers' behavior. There is, however, some work that tries to test which type of model is supported empirically by job seekers’ search behavior. In labor markets with informational frictions, job seekers' search behavior may involve both randomness, such as which job ads to open, and direction, such as which job ads to apply to conditional on opening them. Thus, the question is not so much whether the evidence is completely consistent with one model or the other, but which model provides a better characterization of job seekers' behavior - and, in particular, whether there is evidence that the random search assumption is too simple and we therefore have to allow for directed search. Our goal in this paper is to contribute new evidence on this question from a field experiment.

The prediction that is most commonly tested to attempt to differentiate between the two types of search models is that, holding other things equal, the number of applications firms receive should not vary with the wage offered under random search. However, it should vary with offered wages under directed search (Moen, 1997). In particular, under directed search the number of applications should increase if the potential gain from higher wages exceeds the potential cost from the lower probability of getting the job because higher wages generate tougher competition from more search and applications by other job seekers; if the potential gain is smaller, it should decrease. ${ }^{4}$ This prediction relies on the key assumption in directed search models that job seekers have limited time or resources to apply for jobs, so they need to be

\footnotetext{
${ }^{4}$ As discussed below, the empirical literature examining evidence on directed search mainly focuses on applications as the outcome of interest, because it is difficult to observe search per se, and applications should be a good proxy for search (Belot et al., 2018). Moreover, applications are a better measure of search behavior than hires because higher-wage firms might be more successful in hiring even under random search.
} 
selective in where to apply (e.g., Kircher, 2009). This prediction can be derived from homogeneous worker models, or derived from heterogeneous worker models presenting the average response to wage offers; jobs are always heterogeneous in terms of offering different wages.

When it comes to job seekers of heterogeneous quality, the prediction from directed search models becomes that the application response to jobs offering higher wages should be positively related to the quality of the job seekers, higher-quality job seekers applying more frequently than lower-quality job seekers to high-wage jobs. This is because for high-quality job seekers, the chances of getting high-wage jobs depends only on the number of applications from the other high-quality job seekers, while for low-quality job seekers, competition from highquality applicants lowers their chances of getting hired at high-wage jobs (Faberman and Menzio, 2018; Belot et al., 2018).

In this paper, we present a series of tests for these predictions using data from our field experiment to examine whether and how job search (i.e., applications) responds to the wages offered, for job seekers as a whole, and then accounting for heterogeneous quality. We pay particular consideration to the role of job seekers' reservation wages (RWs hereafter) relative to offered wages - which is central to trying to distinguish between directed and random search.

There is a growing empirical literature trying to test for directed search by investigating the effects of offered wages on job applications. Evidence based on non-experimental data generally lends support to direct search, but is mixed. Some studies find a positive effect (e.g., Banfi and Villena-Roldán, 2019; Cable and Judge, 1994; Krueger, 1988), while others find a negative effect (e.g., Faberman and Menzio, 2018), or a non-monotonic effect (e.g., Holzer et al., 
1991). ${ }^{5,6}$ Marinescu and Wolthoff (2020) obtain mixed evidence, finding that higher wages are associated with fewer applications across job titles within occupations and firms, but more applications within job titles. (It is possible that job titles better capture heterogeneity across workers by reflecting the hierarchy, level of experience, and specialization of different jobs, so that within job titles the effect of wage offer variation is better isolated from variation in other characteristics of jobs.)

However, testing for a causal impact of wages on job applications based on nonexperimental data faces the challenge that variation in wages tends to be correlated with other features of jobs (perhaps included in job ads, or perhaps just assumed by job seekers). ${ }^{7}$ This challenge can be overcome by comparing job seekers' search and application responses to homogeneous real jobs that differ only in exogenously varied offered wages, under the underlying assumption that these jobs are perceived as identical in terms of unlisted job conditions. ${ }^{8}$ In line with this strategy, recent research uses field experiments in which wages for

${ }^{5}$ Some papers focus on the effect on the quality of applicants, in isolation from quantity (Ferraz and Finan, 2009; Crawford and Disney, 2018) or in addition to quantity (Krueger, 1988; Marinescu and Wolthoff, 2020).

${ }^{6}$ Holzer et al. (1991) find that jobs that pay the minimum wage attract more applicants than jobs that pay either slightly more or slightly less than the minimum wage.

${ }^{7}$ For instance, observed characteristics such as words used to describe the job title, as well as region and quarter, explain $57.7 \%$ of the variance of log intended wages and $62.2 \%$ of the variance of log wages when wages are hidden or are posted explicitly in job ads, respectively (Banfi and Villena-Roldán, 2019). Moreover, ads for managerial and highly-paid jobs also tended to request particular sets of skills (Bennett, 2002).

${ }^{8}$ It is possible that job seekers believe that unlisted job conditions vary with the wage. However, in our experiment, at least, this is unlikely to influence our analysis. First, our experimental job ads (and most ads on the job board we use) include many details about the job conditions, including job description, job responsibilities, and employer information, but these details are identical across wage offers for the same position (as explained below, the five positions we use are java engineer, financial executive, human resource manager, marketing executive, and sales executive). And second, the experimental job ads are posted by a single employer, which may minimize any assumed unobserved employer differences. In addition, in an online labor market experiment, Horton and Johari (2018) find that job seekers condition their wage bids on employers' willingness to pay for job seekers' quality when this signal is revealed, but this conditioning is not caused by applicants perceiving job (dis)amenities differently in ways that might be correlated with the signal. 
otherwise identical jobs (in a single occupation) are randomly assigned to real job seekers. This research finds that job applications increase with offered wages (e.g., Abebe et al., 2020; Dal Bo et al., 2013; Deserranno, 2019; Hedblom et al., 2019). ${ }^{9}$

However, another potential issue that most of the existing experimental studies ignore is that job seekers’ RWs can influence whether job seekers apply for certain jobs, generating spurious evidence in favor of directed search if RWs are not considered. In particular, if job seekers use random search but only apply for jobs with offered wages higher than their RWs, one will still find evidence of more applications when offered wages are higher, because the higher the offered wage is, the larger is the share of job seekers for whom the offered wage exceeds the RW (Belot et al., 2018). Thus, without accounting for the RW, a positive effect of offered wages on job applications cannot definitively be viewed as evidence for directed search.

Our paper tries to address both challenges. First, we test for directed search by exogenously varying wages, in a large-scale natural field experiment (Harrison and List, 2004), for otherwise identical real jobs (in multiple occupations) that are offered to real job seekers by a single firm. ${ }^{10}$ Second, we account for how job seekers’ RWs affect their application responses to better distinguish between random and directed search. ${ }^{11}$

Belot et al. (2018) is the only other study of which we are aware that tries to address both

\footnotetext{
9 All of these studies also present some evidence on effects on applicant quality, in each case finding positive effects on applicant quality (measured in different ways).

${ }^{10}$ We use only one firm in our experiment. Although the setting differs from typical models with heterogeneous firms, we are interested in worker responses to wage offers rather than studying equilibrium behavior; that is, our focus is on testing behavioral assumptions about how workers search. In addition, it is common (almost universal) in experiments manipulating behavior of real firms to use only one firm, probably to avoid the logistical difficulties of using multiple firms (e.g., Abebe et al., 2020; Dal Bo et al., 2013; Deserranno, 2019; Hedblom et al., 2019).

11 There is also random variation in job flexibility in the experiment, for which we control in the present analysis. This experiment was originally designed to study job seekers' valuation of flexible working conditions (He et al., 2021). We use the same data to test alternative search models in the present study.
} 
of these issues in testing for directed search. ${ }^{12}$ They bring unemployed job seekers to the lab to search for jobs once a week, for a duration of 12 weeks. Job seekers were informed that fewer than $2 \%$ of the jobs were pairs of fictitious job vacancies posted only for research purposes. One job in the pair offered the original salary of the real job vacancies, and the other offered a higher or lower salary. Belot et al. test the key implications of directed search models that higher wages generate more interest in (the fictitious) vacancies (measured as viewing and saving the vacancies), and that the probability that job seekers who are interested only in the low-wage jobs even if high-wage jobs are present is non-zero - a strategy to avoid competition at high-wage jobs. If job seekers search jobs randomly but only apply to jobs with wages above their RWs, the first test cannot differentiate direct search from this type of random search because interest may increase with higher wages under both models.

Their second test is thus the key test to differentiate these two types of models by examining the "reservation wage property" - a job seeker who encounters two identical jobs and applies to the low-wage one will surely also apply to the high-wage one, as the high-wage one also meets the RW. ${ }^{13}$ Under random search, this property should hold, whereas it should not under directed search due to time or resource constraints in applying for jobs. Belot et al. find affirmative answers to both questions, consistent with directed search. However, the authors do not provide conclusive evidence that perceived competition (obtained via a survey by rating each pair of fictitious vacancies) can explain job seekers’ interest in the jobs controlling for the wage difference, although they do find that job seekers expected to face more competition when

\footnotetext{
12 There are two studies trying to account for RWs when testing for evidence of directed search, based on non-experimental data. Godoy and Moen (2011) use the current wage (as we do), while Braun et al. (2016) use individual demographics such as education and urban status as proxies for the RW. However, both studies face the shortcoming of using non-experimental data.

13 Since they are doing within-individual comparisons over vacancy pairs, the RWs are implicitly held constant.
} 
applying for high-wage jobs. ${ }^{14}$

Two other experimental studies, with seemingly contradictory evidence, also shed light on competition avoiding behavior. Gee (2019) finds that viewing a higher number of applicants to a job does not deter applications, in contrast to the prediction of directed search models. On the other hand, Horton and Johari’s (2018) evidence indicates that allowing employers to signal their willingness to pay for employees with varying quality induces substantial sorting of job seekers by quality, which is consistent with directed search.

Our analysis proceeds in three steps. First, we follow the common practice in existing empirical studies of testing whether higher wage offers attract more applications. However, an affirmative answer to this question alone - without considering RWs - cannot provide decisive evidence of directed search.

Second, we examine whether higher wage offers attract more job applications when wage offers are always above RWs - which is consistent with directed search but not random search. ${ }^{15}$ Because in our data the wage offers are in ranges, as are the measures of RWs, this analysis focuses on job seekers with RWs capped at the upper limit of the lowest wage offer range. By

14 Their design, although innovative, may have some limitations. First, it may suffer from sample selection bias; only about one-quarter of the eligible job seekers they approached participated in the experiment (about half signed up, and about half of those showed up). It may also suffer from sample attrition bias, with subjects leaving the experiment before its end, perhaps due to accepting job offers. Both issues are likely to result in a sample of job seekers with lower quality than average, which could contribute to their finding that a significant share (42\%) of job seekers are only interested in low-wage jobs even when the otherwise identical high-wage jobs are present. Hence, this finding may overstate the evidence for directed search. Second, this study may encounter a potential threat to external validity from inducing the perception of scrutiny, because subjects were pre-informed that a small proportion of vacancies were fictitious and were immediately informed once they saved these fictitious vacancies. Third, there may be an experimenter demand effect because subjects were told the research purpose was "to learn whether they would find these vacancies attractive and would consider applying to them if they were available."

15 The RW is measured by the current/most recent monthly wage, and hence in our context means the minimal wage that a job seeker is willing to accept a new job, rather than the usual meaning of the minimal wage to enter the labor market. We regard this as consistent with how reservation wages are interpreted in job search models, but not in standard labor supply models. 
restricting the sample to the job seekers always having RWs below the higher wage offers (loosely or strictly, as explained later), we eliminate the possibility that the number of applications increases with higher wages because the share of job seekers for whom the offered wage exceeds the RW increases. This step of the analysis differs from the second test in Belot et al. (2018) for the "reservation wage property," in that our offered wages vary across job seekers (i.e., we used a between-subjects rather than within-subject design). This analysis hence examines the pure tradeoff between higher wage offers and the lower probability of getting a job offer, which provides more decisive evidence on directed search.

Third, we test whether, among the job seekers with wage offers always above their RWs, the response to wage offers varies with the RW. We assume that higher quality job seekers have higher RWs, so that the probability of getting a job, conditional on the same wage offer, should increase with the RW, and hence the response to higher offered wages should be stronger for those with higher RWs. Thus, this final analysis addresses how search responds to competition. ${ }^{16}$ Evidence of a stronger response to higher wage offers as the average quality of job seekers improves would provide additional evidence in favor of directed search.

Our findings are consistent with predictions from directed search models. First, in analyses that ignore job seekers’ RWs, higher wage offers significantly raise application rates. Second, higher wage offers raise application rates of job seekers for whom all variation in wage offers is above their RWs. Finally, the positive relationship between wage offers and application rates is stronger for job seekers with higher RWs. All three findings are consistent with directed search, while the second and third findings provide more definitive support for directed search in

\footnotetext{
16 Directed search models explicitly consider the probability of getting a job, thereby incorporating a tradeoff between higher wages and greater competition. In past research, as Kircher (2020, p. 7) concludes in his review, "which individual characteristics are most prone to avoid the competitive but high-paying jobs is not answered... but could be important for future work."
} 
contrast to random search.

\section{Experimental design}

The experimental design was originally developed to study job seekers’ valuation of job flexibility in a prior paper of ours (He et al., 2021). But the same data - used in different ways can be used to assess evidence on directed vs. random search. Since many of the details are provided in our prior paper, here we describe key design features while leaving some of the details out. Also, consistent with our original intention, we only pre-registered the experiment for the initial study. ${ }^{17}$

\section{Experimental setting}

Our field experiment was run on a very large nationwide online job board in China. The job board posts tens of millions of job openings per year with more than 100 million registered job seekers, of whom millions are active each day. The job board specializes in white-collar, high-education jobs, and, correspondingly, job seekers are highly educated.

Designing job ads for the experiment was simplified because the ads are produced using a standard template capturing information about the job and employee requirements. Importantly, the job information includes the range of the pre-tax monthly wage offered (mostly with a fixed monthly rate), or pay is stated as "negotiable."18,19 (Note that we often refer to the "monthly

${ }^{17}$ Prior to data collection, the experiment described in He et al. (2021) was registered on the AEA RCT registry website (AEARCTR-0002645) in December 2017. The registration did not mention the analysis conducted in the present paper.

18 Job ads typically include (from top to bottom) job title, company name, fringe benefits (an employer can list up to eight pre-specified fringe benefits offered), pre-tax monthly salary offered, location (city and district), date of post, nature (full time, part time, internship, or campus), work experience requirement, educational degree requirement, number of vacancies, occupation, job responsibilities, job requirements, address of the job, etc. Appendix A provides more details on the fringe benefits offered, and also presents evidence on fringe benefits as an additional mechanism to attract job applicants.

${ }^{19}$ We use the non-experimental data to compute the proportion of jobs that are advertised with wages. Specifically, we collected all full-time job ads posted for the five occupations studied in our experiment 
wage” simply as the "wage.” We use the word “salary” when we refer to yearly pay, and sometimes refer to the "monthly salary.”)

We collaborated with a start-up company in the information technology (IT) industry. The company had real recruitment demand for several positions and was interested in exploring how varying wages offered (and flexible working conditions) would affect its recruitment. IT jobs are common on the job board (about $40 \%$ of jobs, based on the non-experimental job ad data we collected). Using a small (20-99 employees) and not well-known company helped minimize the effect of our intervention on the market. Using a single employer keeps the employer-specific characteristics fixed across jobs. We transferred the résumés of the job applicants to the company, and its HR department contacted selected applicants for further recruitment procedures. $^{20}$

The five job positions included in the experiment - java engineer, financial executive, human resource manager, marketing executive, and sales executive - were dictated by the demands of the company. These could be classified in the following broader occupations that could be listed on the job board: software, finance, personnel (human resources, or HR), marketing, and sales management.

Job seekers need to first register and provide individual information to construct a standardized résumé. The required information includes, among other things: the current (if currently employed) or most recent (if currently non-employed) job’s monthly wage (pre-tax),

(software, finance, personnel (human resources, or HR), marketing, and sales management), for jobs located in Beijing, between November 20, 2017 and March 2, 2018. This period covered 5 weeks before, 5 weeks after, and 4 weeks during the implementation of our experiment, which was conducted between January 4 and February 1, 2018. These criteria yielded ads for 342,152 jobs. Out of these jobs, 97.7\% specify monthly salary ranges. Therefore, testing a directed search model in such a setting is appropriate, as opposed to a setting where wages are not advertised (posted).

20 As far as we know, the company contacted 87 applicants for interviews and the rest of them received a rejection letter via their account on the job board. 
and generic monthly wage expectations (pre-tax). ${ }^{21,22}$ After registering and logging in, job seekers can apply to job ads listed on employers' webpages or searched using a search bar. When they click on an ad, they see a full-page description, and they can then click the "Apply" button in the ad to apply for that job and send their generated résumé to the employer. The employer then receives the generated résumé along with contact information. Most employers choose to contact applicants offline outside of the job board's communications system, by telephone or email, so the job board does not capture the subsequent outcomes of the search process (e.g., callbacks, job offers, and pay). ${ }^{23}$

We define the population of eligible job seekers targeted by our experiment based on the following criteria: (1) residence in Beijing at the time of the experiment; (2) college degree or higher; (3) active in job search (having logged onto their job board account within one month from when we first extracted their résumés for consideration for inclusion in the experiment); ${ }^{24}$ and (4) a match between any of the "intended occupations" chosen by the job seeker (they could indicate up to three) and our chosen occupations. ${ }^{25}$ We drew the population of job seekers for

${ }^{21}$ Both variables are measured in ranges, selected from a drop-down menu, including below 1,000, 1,001-2,000, 2,001-4,000, 4,001-6,000, 6,001-8,000, 8,001-10,000, 10,001-15,000, 15,001-25,000, 25,001-35,000, 35,001-50,000, 50,001-70,000, 70,001-100,000, and above 100,000 CNY. Job seekers can choose not to reveal this information to potential employers.

22 The other required information includes: individual details (name, contact information, gender, year and month of birth, year and month started first job, place of Hukou, highest educational degree and dates of start and completion, school name, major, and overseas work/study experience); information about work or internship experience (industry, job title, and length of job); type of job sought (occupation, industry, and location); current work status (employed or not). Providing marital status is optional.

${ }^{23}$ This information, as well as other information about how the job board works in practice, was provided to us in conversations with staff at the job board.

${ }^{24}$ The one-month cutoff was chosen to correspond to the usual definition of unemployment. In the United States a worker is defined as unemployed if she searched for a job in the past month (see https://www.bls.gov/cps/cps_htgm.htm\#unemployed, viewed August 15, 2018). In China, the criterion is three months (see http://www.stats.gov.cn/tjsj/tjzd/gjtjzd/201807/t20180717_1610135.html, in Chinese, viewed August 18, 2018). We chose the more restrictive U.S. standard to have a more active sample of job searchers for whom the data would be more up to date.

${ }^{25}$ For a job seeker who had multiple "intended occupations" that matched our occupations, we randomly assigned her to one of the jobs using equal probabilities. 
the study, which was all job seekers registered on the job board fulfilling these criteria, one week before the experimental contacts were made.

\section{Treatments}

The treatment manipulation we exploit in this paper is the pay variation that was part of the manipulation in the experiment conducted in He et al. (2021). Specifically, in the present study, we used a $1 \times 3$ between-subjects factorial design in which we exogenously varied the pre-tax monthly wage offered for the same posted jobs in three ranges: 10,000-15,000 CNY, 15,000-20,000 CNY, and 20,000-25,000 CNY, which are referred as Low, Medium, and High level treatments, respectively. ${ }^{26,27}$ These ranges were derived from the distribution of wage ranges of over 8,000 real job ads we collected from the job board a few months before our experiment, which were recruiting for our five experimental occupations and required at least college education and at least 5-10 years of work experience, which are also the education and experience requirements of our experimental jobs. ${ }^{28,29}$

The wage offer range treatment conditions were presented in the job ad emails and app messages that were sent to the subjects. The email pushing and message pushing - through which job invitations are sent to potentially suitable candidates based on matching algorithms -

${ }^{26} 1 \mathrm{CNY}=0.15$ USD at the time of the experiment in early 2018. We used a monthly wage instead of an hourly wage in the experiment because it was natural for full-time jobs of similar types (most ads on the job board) to set a fixed monthly wage. We also explicitly mentioned in the job ads that the work day was eight hours, to try to preclude higher wages being viewed as compensation for longer working hours.

${ }^{27}$ Given the goal of the original experiment, we also manipulated the flexibility of working conditions. These are orthogonal to the pay variation, but we retain the flexibility conditions as control variables in our analysis.

${ }^{28}$ We separately computed the $25^{\text {th }}, 50^{\text {th }}$, and the $75^{\text {th }}$ percentiles for the lower and upper limits of the wage ranges $(10,001,15,001$, and 20,001 CNY for the lower limits, and 15,000, 20,000, and 30,000 CNY for the upper limits). Appendix Figure B1 provides the distributions of the lower and upper limits of wage ranges of the 8,000+ jobs. To keep the width of the ranges comparable, we used 25,000 as the upper limit for the high range. We also computed the corresponding wage range distributions for the five experimental occupations and found that they were similar to the full sample.

29 Employers could select from no degree requirement, below college, college, bachelor, or master or above, and could select from no experience requirement, $0-1,1-3,3-5,5-10$, or $>10$ years. 
are two services the job board provides to employers to facilitate matches between jobs and workers. ${ }^{30}$ Email pushing entails sending a brief description of selected job openings via email to candidates. Message pushing plays a similar role. Both emails and messages include a link to the full job ad. A job seeker typically receives one or two emails and app messages per day during the time she frequently logs onto her account or searches for jobs.

In job ad emails, the treatment condition appeared in both the subject line and right after the title of the job position with highlighted fonts in the main body of the emails. The app messages simply contained information on the job title and the wage offer range for each treatment. Both the job ad emails and app messages included a link to the job ad. Appendix C presents examples of the job ad email and the app message for the financial executive position. The job ads also appeared on the company's webpage, and because job seekers in the experiment were directed to the webpage (as explained below), we wanted to ensure that job ads there appeared the same. They were identical, except that we set the monthly wage offered to be “negotiable” in the job ads published on the company's webpage, to avoid direct contradictions with variation in wage offer ranges in the emails and app messages. ${ }^{31}$ Appendix D provides an example of the job ad, for the financial executive position.

\section{Experimental procedure}

\footnotetext{
30 The matching algorithms can rely on information in the résumé (e.g., the monthly salary offered in the job matches the monthly salary expectation of the job seeker, and occupation or industry of the job matches the job seeker's intended occupation or industry), job seekers' previous job search behavior (e.g., the occupation or industry of the job matches the occupation or industry in which the job seeker searched in the past), or application behavior on the job board (e.g., the occupation or industry of the job matches the occupation or industry in which the job seeker has previously applied). Employers can define some parameters of the matching algorithm for their postings (e.g., pushing ads to those with a college degree or working in a particular industry).

31 It would have been far more complex, and perhaps not feasible, to try to coordinate the company's webpage job ads to vary with the timing of our treatments. Specifying the wage as "negotiable" is not contradictory to what the emails and app messages say, since it can be negotiable within the indicated pay ranges.
} 
Our experiment includes an application stage and a survey stage, which enable us to collect job seekers’ application decisions, and then questionnaire completion decisions conditional on applying. In the application stage, the company published the job ads on the job board, and then the job board pushed the corresponding job ads via both emails and app messages to the population of eligible job seekers, with one job seeker being sent one ad. The job ads of the five job positions were published simultaneously on Thursday morning and all ads stated that the application deadline was 9 AM the following Wednesday. For the job seekers who were sent emails and app messages, applying for a job involves two steps. First, they needed to click the link to the job ad, which directed them to the corresponding job ad on the employer's webpage on the job board. Second, they needed to click the "apply” button on the webpage. The redirection from the email or app system to the webpage was standard for all email or message recipients contacted through these means, and applications taken on the job board could be recorded. Any job seeker, whether or not they were sent an email or an app message, could search the job board and find and apply for the experimental jobs. ${ }^{32}$ Applying for the experimental jobs serves as the primary measure of interest in our jobs.

In the second stage, we sent an email and a text message to all job seekers who had applied for our jobs, inviting them to voluntarily answer an online questionnaire within three days, prompting them by writing: "Your qualifications match our position well. We would like to know more about you." 33 We did not provide additional incentive to respond to the questionnaire because we believed job seekers who were interested in the job would have enough incentive to complete the questionnaire, and it seemed unnatural for a company evaluating job

32 The applications made by job seekers who were not sent the email or app message are excluded from our analysis.

33 The information collected was used in our original experiment (He et al., 2021). 
applicants to offer incentives to complete the survey. Completion of the questionnaire required additional effort and thus serves as an alternative measure of interest in our job, which we use in a parallel analysis to our analysis of job applications as, effectively, an alternative measure of applying for the job.

Compared to the procedure adopted by Flory et al. (2015) and Hedblom et al. (2019), in which randomized treatment conditions were revealed only after job seekers had expressed interest in the job by emailing their résumés, our treatment conditions were presented to job seekers in the job ads at first contact. In our view, this procedure had two advantages: it preserved the normal way of presenting key job conditions on the job board we used, and it allowed us to collect data on responses to treatment conditions in one stage.

The experiment was conducted in January and early February of 2018. We randomly assigned eligible job seekers into various wage offer conditions and gave the subsample for each treatment to the job board to operate the email and app message pushing. Throughout the experiment, there were no communications between the job seekers and the experimenters, except for the carefully scripted job ad emails and app messages sent in the first stage, and emails and text messages regarding questionnaire completion in the second stage.

\section{Results}

The key outcome data collected from the experiment include the individual-level data on who applied for the experimental jobs and who completed the questionnaire. As outlined in the introduction, we present results addressing three questions:

(1) Do applications respond positively to higher wages, without considering RWs, which can provide some evidence of directed vs. random search?; (2) Do applications respond positively to higher wages, conditional on offered wages exceeding job seekers' RWs, which 
provides more decisive evidence on directed vs. random search?; and (3) Is a positive response of applications to offered wages stronger the higher the probability that the job seeker would get the job (based on higher RWs), consistent with directed search?

\section{Do higher wages attract more applications, ignoring reservation wages?}

We first test the prediction of directed search models that job seekers apply more for higher wage jobs that are otherwise identical. Here we simply follow the common practice of most of the previous empirical studies without considering the role of RWs.

Table 1 reports the distributions of applications and questionnaire completion across treatments. The total number of job seekers in the experiment is 99,178, almost equally distributed across wage offer ranges. ${ }^{34}$ In the upper panel, the application rates reported in the last column are computed as the number of applications divided by the number of job seekers who were sent job ad emails and app messages. The application rates for all treatments are below 0.5\%. Application rates are low because there are thousands of job openings posted every day, presumably with many job descriptions similar to ours, so that getting an email or an app message as part of the experiment would not be expected to generate a large number of applications. ${ }^{35}$ Nonetheless, the application rates are 22\% and 50\% higher for Medium and High

\footnotetext{
${ }^{34}$ Appendix Table E1 reports summary statistics on job seekers' individual characteristics for each treatment, to assess the randomization. In the self-reported résumé data on individual characteristics, there are sometimes inconsistencies related to the dates of events reported, such as a birth date later than other events like the start of highest degree education or a first job, or start dates for specific spells (such as education) that are later than ending dates. There are also some less clear inconsistencies, such as completing education at too young an age (e.g., completing college before age 18 or university before age 20). We clean the data to eliminate these kinds of inconsistent cases whenever individual characteristics are considered. This results in excluding fewer than $1.6 \%$ of observations. The mean differences for almost all variables are small across treatments. We also ran pairwise (across three treatments) Kolmogorov-Smirnov tests of equality of distributions of these characteristics. We find no significant differences at conventional levels. In the regressions we control for these characteristics anyway, and we find that our estimated treatment effects do not vary whether or not we control for these characteristics.

35 Personal conversations with the staff at the job board indicated that a $0.5 \%$ rate of application for job ads pushed to job seekers is typical.
} 
wage jobs, respectively, than for Low wage jobs, and 23\% higher for High wage jobs than for Medium wage jobs; the differences are statistically significant at the $1 \%$ or $10 \%$ level for the latter two comparisons, based on tests of equality of proportions.

Another indicator of interest in the experimental jobs is whether the job seekers completed the questionnaire. ${ }^{36}$ In the lower panel of Table 1 , the completion rates reported in the last column are computed as the number of applicants who completed the questionnaire divided by the number of job seekers who were sent job ad emails and app messages. ${ }^{37}$ The completion rates show that $0.2 \%-0.3 \%$ of job seekers completed the questionnaire; the rates are 36\% and 75\% higher for Medium and High wage jobs, respectively, than for Low wage jobs, and 29\% higher for High wage jobs than for Medium wage jobs; the differences are statistically significant at the $1 \%$ or $10 \%$ level for all three comparisons.

Next, we turn to regression analysis. Table 2 reports the differential effects of the wage offer treatments on application and questionnaire completion decisions, with Low wage as the reference group, estimated from a probit model. The dependent variable in columns (1)-(3) is an indicator for whether the job seeker applied, and in columns (1')-(3') for whether the job seeker completed the questionnaire. We present the implied percentage changes in the application or completion rate, relative to the comparison groups, in the top panel, and the marginal effects from the probit estimation in the bottom panel.

Column (1) includes only the treatment dummy variables. We find evidence that High wage offers significantly boost application rates - by 50\% compared to an application rate of

\footnotetext{
36 The two outcomes applying or not, and completing the questionnaire or not, are highly correlated: the overall correlation is 0.79 , and both the correlations and the questionnaire completion rates conditional on application do not differ much across Low, Medium, and High wage offers. (See Appendix Table E2 for more details.)

37 Because we use this as an alternative indicator of “applying," we do not condition on applying.
} 
0.27 percentage point for Low wage offers. This is computed based on a 0.14 percentage point increase (the marginal effect) relative to Low wage offers. ${ }^{38}$ The estimates in column (1) also indicate that the application rate is significantly higher (at the 5\% level) for High wage offers relative to Medium wage offers; the implied effect is a $31 \%$ increase. The estimated effect of Medium wage offers relative to Low wage offers is not significant, although it is positive.

The increase in the monthly wage from Low to High wage offers is about $80 \%$, and the increase from Medium to High wage offers is about $29 \% .{ }^{39}$ Converting our estimated treatment effects to elasticities, our estimated elasticities are 0.62 for High vs. Low offers and 1.09 for High vs. Medium wage offers. These are comparable in magnitude to the results in Dal Bo et al. (2013), who find that a $1 \%$ increase in wages leads to a $0.79 \%$ increase in applications, and Belot et al. (2018), who find that a $1 \%$ increase in wages leads to a $0.7 \%-0.9 \%$ rise in applications.

Column (2) adds controls for job characteristics - the job flexibility condition and job position dummy variables; column (3) further adds controls for job seekers’ individual characteristics. The estimates change very little. ${ }^{40}$

The analysis for questionnaire completion is reported in columns (1')-(3'). It uses the same specifications as in the analysis for applications, and the results are qualitatively similar. As the top panel of the table shows, the relative (percentage) effects of higher wage offers on the

\footnotetext{
38 Although the marginal effects are fairly small mainly due to a low "baseline" response rate, the relative (percentage) effects are sizable.

${ }^{39}$ For example, the monthly wage offer range midpoint difference between High and Low wage levels is 10,000 CNY. Dividing the difference by the midpoint of Low wage offer range 12,500 gives a wage offer increase of $80 \%$.

40 Appendix Table E3 reports the summary statistics for the individual characteristics of job seekers and the treatments, job flexibility conditions, and occupations for this regression sample. Complete regression results showing the estimated marginal effects of all job and job seeker characteristics are available from the authors upon request. To briefly summarize the findings for the latter: the application rate rises with job flexibility, work experience, the other four job positions relative to java, male, married, currently employed job seekers, and those expecting to work in Beijing.
} 
probability of completing the questionnaire are larger in most cases than those on the probability of applying (the estimated differences in the marginal effects in the bottom panel are smaller due to a lower "baseline" questionnaire completion rate).

Overall, the findings on job application rates - whether measured directly or based on the more-intensive measure of questionnaire completion - show that job seekers are more likely to apply for higher wage jobs, in line with most of previous empirical studies. This evidence could be more consistent with direct search than random search, but our next two analyses are needed to obtain more definitive evidence.

Do higher wages attract more applications, for wage offer variation above reservation wages?

As discussed in the Introduction, evidence of a positive response of job applications to higher offered wages is not definitive evidence in favor of directed vs. random search because job seekers using random search may only apply for jobs with offered wages higher than their RWs, also generating evidence that higher offered wages attract more applications even though job seekers are not using directed search. To better differentiate whether job seekers use random search and simply apply when offered wages exceed RWs, or instead use directed search, we restrict our sample to job seekers with RWs capped at 15,000 CNY, which is the upper bound of the Low wage offer range, and re-estimate the specifications in columns (3) and (3') in Table 2.

The conclusions from this analysis hinge on our having a reliable measure of the RW. Thus, before turning to the results of this analysis, we discuss evidence on the reliability of the RW measure.

One issue is which measure to use. We have two alternative measures of the RW from job seekers' résumés - the generic wage expectation, and the current/most recent wage. We use the current/most recent wage, because for a number of reasons this measure is much more likely 
to be accurate. Most importantly, it is common in China for prospective employers to ask for bank statements showing previous wage payments as part of background checks before hiring, creating a strong incentive for job searchers to report this information accurately. In addition, since the current/most recent wage in a similar job should approximately be the worker's marginal productivity, this information is valuable to employer in learning about the worker before extending a job offer (Barach and Horton, 2021), and workers anticipating this have an incentive to report accurately (or at least not to understate). Finally, the current/most recent wage is a more natural reference point to determine the RW for accepting a new job. In contrast, a generic “wage expectation” need not be constrained by these factors.

We also looked at other data sources to confirm the accuracy of the RW data. First, we compare our RWs with administrative wage data. ${ }^{41}$ The average monthly pre-tax wage in Beijing was 9,595 CNY at the end of 2017 (Beijing Municipal Bureau Statistics, 2018), and the average of our RW measure (based on range midpoints) for the sample of 94,408 job seekers who disclose this RW measure is 9,563 CNY. These are very close. Second, to provide some evidence on the average wages specific to the occupations of the job seekers in our experiment, we compared the pre-tax monthly wages offered in the ads of the jobs that the job seekers in our experiment applied for in the 5 weeks prior to our experiment (over 2 million jobs) with their RWs. The average wage offer midpoint for the sample of job seekers who disclose their RW and

\footnotetext{
${ }^{41}$ We are not aware of any survey or administrative data on RWs in China (and in fact we would imagine that data on RWs is rare - perhaps available only in countries with active job placement institutions). The best we can do, we think, is to compare our average RW data (the current/most recent wage midpoint) with the pre-tax monthly average wage for employees of all legal entities in Beijing at the end of 2017 from administrative data. We compare to the 2017 average wage because our experiment was conducted in January and early February of 2018. We compare to the average wage for Beijing, instead of for all of China, because subjects in our experiment are eligible job seekers who at the time of the experiment resided in Beijing. Beijing had the highest average wage for employees in both state and private working units among all provinces in China in 2017 (National Bureau of Statistics of China, 2018).
} 
who applied for at least one other job with a non-missing wage offer is $11,986 \mathrm{CNY}$. ${ }^{42}$ The average RW midpoint in this sample is 9,514 CNY. The correlation between average wage offers and RWs is 0.54 , statistically significant at the $1 \%$ level, suggesting that these two wage measures are highly correlated. Of course it is not surprising that RWs are below offered wages, whereas the reverse would be a concern with the RW measure. Indeed, among job seekers who disclose their RW and who applied for at least one other job with a non-missing wage offer, only $19.3 \%$ of the jobs they applied for had wage offers below their RWs. ${ }^{43}$ We regard that as a quite low percentage. (After all, there can be differences across jobs that might induce workers to sometimes apply for jobs that pay less than their posted RW; they do not post a RW for each different job so that we cannot be completely definitive about violations of this condition.)

In addition, some features of the data support the choice of using the current/most recent wage as the RW. First, there are more observations on current/most recent wages available for analysis. In the job seekers in our experiment, 95.2\% disclose current/most recent wages, whereas only $82.5 \%$ disclose generic wage expectations. Moreover, in the sample of 328 applicants to our experimental jobs, 305 disclose current/most recent wages, whereas only 231 disclose generic wage expectations. Second, there are fewer cases of applications made to jobs offering wages below current/most recent wages. As just noted, $19.3 \%$ of the jobs that the job seekers in our experiment applied for in the 5 weeks prior to our experiment had wage offers below their current/most recent wages, whereas the corresponding percentage is $25.7 \%$ when RWs are measured by generic wage expectations. The experimental data lends further support. Fewer than 8\% (24 out of 305) applicants applied for jobs that offered wages below current/most

${ }^{42}$ In total, 46,610 out of 99,178 job seekers in our experiment applied for other jobs 5 weeks prior to our experiment; 41,293 out of 46,610 are in the sample with RW disclosed and the wage offer non-missing.

43 "Below" means that the upper limit of wage offer range is below the lower limit of the RW range. 
recent wages, whereas more than 15\% (36 out of 231) did so when the RW is measured by generic wage expectations. Finally, we have verified that the results are robust to using the generic wage expectation as a proxy for the RW (Appendix Table E4, which can be compared with Table 3, discussed below).

Next, we explain why we cap the RW at 15,000 CNY to test for effects of wage offer variation above the RW. Given the ranges we have for RWs and wage offers, this cap allows the inclusion of the largest subsample while also making it likely that the variation in wage offers exceeds the RW. Given that the Low wage offer range is 10,000-15,000 CNY, when we use a 15,000 cap for the RW it is possible that a wage offer in the Low wage offer range can exceed the RW - e.g., if the actual RW is 14,000 and the job seeker interprets the 10,000-15,000 wage offer as likely to pay less than 14,000. In contrast, offer wages above 15,000 CNY must exceed the RW when it is capped at 15,000. We could avoid the potential ambiguity by imposing a RW cap of 10,000 , but this substantially reduces the sample size. Because of the potential ambiguity regarding RWs and the Low wage offer range, when we study all three wage offers with this cap imposed on the RW, we refer to the resulting sample as the "less restrictive" sample. However, we also present results using “more restrictive” sample (detailed below) for which all offer wages must exceed the RW, and obtain similar results.

To return to our question, recall that estimates indicating that job applications respond positively to higher wage offers conditional on those wage offers exceeding RWs would provide evidence in favor of directed search over random search. Columns (1) and (1') in Table 3 report the estimation results. For application decisions, in column (1), High wage offers raise application rates of job seekers relative to Low wage offers by a statistically significant 0.10 percentage point. Compared to an application rate of 0.40 percentage point for Low wage offers, 
this represents a $25 \%$ increase in application rates. Medium wage offers do not significantly raise the application rate relative to Low wage offers. In addition, the application rate is significantly higher for High wage offers than for Medium wage offers. Compared to an average application rate of 0.45 percentage point for Medium wage offers, the estimate implies a $19 \%$ increase in application rates. The result for questionnaire completion in column (1') is qualitatively similar and quantitatively a bit smaller (although the relative effects are larger). Compared to the results in Table 2 columns (3) and (3’), the treatment effects are smaller.

To rule out the possibility that the wage offer was below the RW, we also do this analysis using a more restrictive sample - the subsample of job seekers who were sent Medium and High wage offers and have RWs no higher than 15,000 CNY; this guarantees that wage offers exceed RWs. Columns (2) and (2') in Table 3 report the estimation results. We find a significant application rate increase for High relative to Medium wage offers (at the $10 \%$ level). ${ }^{44,45}$

Overall, the findings on job application rates - whether measured directly or based on the more-intensive questionnaire completion measure - show that job seekers are still more likely to apply for higher wage jobs even when the offered wage variation is above their RWs. This provides more definitive evidence in favor of directed search. Is the response of applications to higher offered wages stronger for those with a higher probability

${ }^{44}$ Even with measurement in ranges, the RW measure may contain some measurement error. For instance, workers' RWs for new jobs might be higher than their current/most recent wage if they require a pay increase to compensate for the cost of switching jobs. In such a case, with our cutoff of 15,000 CNY, we might incorrectly classify a RW as below the wage offer when it is in fact above the wage offer. However, as long as the actual RW is no more than 5,000 CNY higher than the current/most recent wage, the corresponding actual RW cutoff would not exceed 20,000 CNY, which is the upper bound of our Medium wage offer range. Therefore, job seekers receiving our High wage offers would always have actual RWs below the wage offers. Thus, our analysis for the more restrictive sample in Table 3 - which supports the finding of directed search - would still be valid.

45 We also explored the potential role of selection bias pertaining to missing RW data, and missing job seeker characteristics. We estimated our key specifications from Tables 2 and 3, and show that the results are not sensitive to these sample restrictions. (See Appendix F.) 
of getting the job?

Finally, we explore whether the positive relationship between wage offers and job applications varies across job seekers in relation to their probability of getting the job, as proxied by their RWs. We use the same samples as in the prior test, restricting attention to variation in offered wages above the RW. ${ }^{46}$ A stronger positive effect of higher wage offers on job applications when we increase the RW cutoff (keeping it below 15,000 CNY, as before) would provide additional evidence in favor of directed search. This is because job seekers with higher RWs are (we assume) of higher quality, and hence for the same offered wage should view themselves as more likely to get the job in competition with other job applicants. Therefore, under directed search, the degree of responsiveness to the higher wage job should be positively related to the competence of job seekers as proxied by their RW, while the two should be unrelated under random search.

For this analysis, there is a potentially important issue regarding measurement of the RW. In particular, in this analysis we are testing whether job applications are higher for those with higher RWs. Suppose, however, that less active job seekers do not update their RWs on the job board. In that case, we might find higher job application rates for those with higher RWs not because job seekers respond to the higher probability of getting a job, but for the spurious reason that those with lower RWs posted in the past, when they were young, are not currently searching actively.

There are two reasons we do not believe we have a problem from older and outdated RWs for less active searchers. First, we have restricted the sample to those who are fairly active,

\footnotetext{
46 This restriction to offered wages above the RW rules out the possibility that a worker is too highlyqualified for a job, in the sense that her RW exceeds the willingness of the employer to hire the worker. Without this restriction, the possibility could occur, in which case the probability of getting a job could decrease for workers with higher RWs.
} 
i.e., having visited the job board in the past month. On its own, this screens out inactive searchers. ${ }^{47}$

Second, it is reasonable to expect that if people update their RWs, we should observe a positive cross-sectional relationship between RWs and age. People typically join the job board at similar young ages when they are in college searching for internships, and then to look for jobs at graduation. (Recall that we restrict attention to those with at least a college degree.) Thus, whether they update or not, people will generally first post RWs roughly at the age when they finish college. On average, younger people should have lower RWs than older people at a point in time, due to the greater work experience of older workers, implying higher human capital and hence higher productivity. Thus, if people update their RWs, RWs should be higher for older job searchers. In contrast, suppose people do not update their RWs, but just post them when they leave college and (to be extreme) leave them unchanged. In that case, RWs should be higher for more recent (i.e., younger) cohorts because of rising wages (and productivity) generally. Thus, if RWs are not updated, we should find a negative cross-sectional relationship between RWs and age. The evidence indicates, in fact, that the cross-sectional RW-age profile is unambiguously positively sloped, consistent with updating of RWs. ${ }^{48}$

Before implementing our test for directed vs. random search, we first investigate whether job seekers with higher RWs have higher values of observed characteristics related to worker quality. We use currently employed, tenure on the current job (zero if not employed), years of work experience, education, and whether the current/most recent job was in IT-related industries

\footnotetext{
47 We do not have a more-detailed direct measure of activeness, such as site visits to search in a given time window.

48 The results are described and reported in Appendix G.
} 
(which could reflect industry-specific human capital, or general ability). ${ }^{49}$ Table 4 reports the summary statistics of these characteristics for each RW range. ${ }^{50}$ In nearly every case, these quality measures are increasing with the RW, consistent with job seekers with higher RWs being higher quality.

Finally, we report evidence on differences in the effects of wage offers on job applications associated with variation in RWs. One analysis of the estimated impact of wage offers on job applications across job seekers with different RW lower cutoffs within the subsample capped at 15,000 CNY is reported in Table 5, including (columns (1) and (1')) and then excluding (columns (2) and (2')) job seekers who were sent Low wage offers. ${ }^{51}$ We can see that regardless of the job application measure used, or the inclusion of job seekers who were sent Low wage offers, as we raise the lower RW cutoff from 2,001 to 10,001 CNY, the treatment effects (especially the effects of High wage offers) become stronger in both magnitude and statistical significance.

To provide a statistical test of whether the application response to the wage offer is stronger for higher RWs, we adopt a more parsimonious approach. In particular, we create a single RW variable based on the midpoint of the RW bins, and introduce interactions with the wage offer indicators. Table 6 reports the effect of the RW on the marginal effect of higher wage

${ }^{49}$ IT-related industries include: IT service; e-commerce; online game; computer hardware; computer software; communications/telecom \& network equipment; communications/telecom operations; and value-added services. This is a subset of the 52 industries job seekers can indicate.

${ }^{50}$ We omit job seekers with RWs below 2,000 CNY in this analysis, for two reasons. First, job seekers with RWs this low are abnormal given the monthly minimum wage in Beijing was 2,000 CNY at the time of the experiment (Beijing Municipal Human Resources and Social Security Bureau, 2018). Second, the numbers of applications and of job seekers for RW ranges below 2,000 CNY are small, so omitting them would not change the results.

51 An alternative way to compare the relationship for job seekers across different RWs is to do the analysis for job seekers separately in each narrow RW range implied by the ranges in Table 5 (e.g., 2,000 to $4,000,4,000$ to 6,000 , etc.). However, this led to some very small samples with large numbers of perfect predictions for the probit models (recall that the overall application rate is low), and hence problems of both estimation and interpretation. 
offers (evaluated at the mean of the RW), i.e., the implied interaction effects of the RW $\times$ wage offer. The differential application responses of High vs. Low and High vs. Medium are a good deal higher at higher RWs, although the estimated differential is statistically significant only in column (2); the p-values of the other interactions for High vs. Medium or Low are all below 0.15. These results indicate that a higher RW increases the effects of higher wage offers, although the evidence is not always strong statistically. Overall, we view Tables 5 and 6 as providing additional evidence in favor of directed search over random search, and suggesting that the more competent job seekers are (i.e., the higher their probability of getting the job), the more strongly they respond to higher wage offers. ${ }^{52}$

Note that the RW might have some measurement error, because it is elicited once on the job board, and hence does not reflect variation in the wages at which an individual would accept a particular job. If there is measurement error in the RW, the data sometimes misclassify people by their RWs. This would bias the results against finding differences in response to wage offer variation by the RW, which implies that our results would if anything be somewhat stronger if we had unique RWs depending on the job. Similarly, we noted earlier that the algorithm parameters for which jobs are pushed to workers can be influenced in part by employers. But presuming that, if anything, high-quality workers are more likely to be pushed high-paying jobs, and low-quality workers low-paying jobs, our estimates indicating stronger responses of applications to higher wage offers for those with higher RWs provide lower bounds on how workers of different qualities respond to wage offers. That is, if high-quality workers were

52 Since our offered wages vary across job seekers (i.e., we used a between-subjects rather than withinsubject design), our result shows how different job seekers apply to high-wage compared to low-wage jobs (though they are similar on observables), rather than showing how one particular job seeker sometimes avoids high-wage jobs in favor of low-wage jobs because high wage jobs are more competitive (as in Belot et al., 2018). 
pushed high-paying jobs, our job being a similar one as other jobs would be less likely to draw their attention and consequently be applied to. And if low-quality workers were all pushed lowpaying jobs, our job being a distinct one from other jobs would be more likely to draw their attention and consequently be applied to. Therefore, absent this effect, our evidence that higherquality workers respond more strongly to higher wage offers would be even stronger.

\section{Conclusions}

We explore evidence on random vs. directed search using data from a field experiment on a Chinese job board. In the experiment, we generate random variation across job seekers in invitations to apply for jobs that differ in terms of wage offers, in three ranges (High, Medium, and Low). The experimental data allow the estimation of application responses for job ads that are otherwise identical, free from the potential bias that can arise in non-experimental data when wage variation is correlated with other job characteristics. We also use the current/most recent wage from job seekers' résumés as a proxy for their reservation wage (RW) for accepting a new job. Combining these data allows the estimation of application responses to exogenous wage variation that is above the job seekers' RWs, which is important for distinguishing between random and directed search.

Our findings provide evidence in favor of directed search over random search. First, in line with previous field experiments, higher wage offers (ignoring RWs) significantly raise application rates. Second, for wage variation above RWs, higher wage offers raise application rates, which provides more definitive evidence of directed vs. random search, because the first type of evidence could simply reflect whether the wage offer resulting from random search is above the reservation wage, which would also raise application rates under random search. Finally, among job seekers with wage offers always above their RWs, the response to higher 
wage offers is stronger for job seekers with higher reservation wages; this provides additional evidence for directed search because it implies that job seekers respond not only to the higher wage offer but to variation in the probability of getting a job.

There are two natural directions in which this research could be fruitfully extended. First, the external validity of our findings could be strengthened if one could run the experiment in a broader range of cities, industries, and firms. Second, while our study provides evidence of directed search in the labor market, it would be valuable to quantify how much directed search is used compared to using random search - exploring questions such as what proportion of job seekers uses directed search, and to what extent a job seeker uses directed search and under what circumstances. 


\section{References}

Abebe, G, Caria, S \& Ortiz-Ospina, E. 2020. The selection of talent: Experimental and structural evidence from Ethiopia. American Economic Review, forthcoming.

Acemoglu, D. 1997. Training and innovation in an imperfect labour market. Review of Economic Studies, 64(3), 445-464.

Acemoglu, D., \& Shimer, R. 2000. Productivity gains from unemployment insurance. European Economic Review, 44(7), 1195-1224.

Banfi, S., \& Villena-Roldán, B. 2019. Do high-wage jobs attract more applicants? Directed search evidence from the online labor market. Journal of Labor Economics, 37(3), 715-746.

Barach, M., \& Horton, J.J. 2021. How do employers use compensation history? Evidence from a field experiment. Journal of Labor Economics, 39(1), 193-218.

Belot, M., Kircher, P., \& Muller P. 2018. How wage announcements affect job search - a field experiment. IZA Discussion Paper No. 11814.

Beijing Municipal Bureau Statistics \& Survey Office of the National Bureau of Statistics in Beijing. 2018. Beijing Statistical Yearbook. China Statistics Press, Beijing.

Beijing Municipal Human Resources and Social Security Bureau. 2018. Notice on adjusting the minimum wage standard of Beijing in 2018. http://rsj.beijing.gov.cn/xxgk/zcwj/201912/t20191206_943464.html, accessed on March 6, 2020.

Bennett, R. 2002. Employers' demands for personal transferable skills in graduates: A content analysis of 1000 job advertisements and an associated empirical study. Journal of Vocational Education and training, 54(4), 457-476.

Braun, C., Engelhardt, B., Griffy, B., \& Rupert, P. 2016. Do workers direct their search? UCSanta Barbara Working Paper.

Cable, D. M., \& Judge, T. A. 1994. Pay preferences and job search decisions: A personorganization fit perspective. Personnel Psychology, 47(2), 317-348.

Crawford, R., \& Disney, R. 2018. Wage regulation and the quality of police applicants. Economica, 85(340), 701-734.

Dal Bo, E., Finan, F., \& Rossi, M. A. 2013. Strengthening state capabilities: The role of financial incentives in the call to public service. Quarterly Journal of Economics, 128(3), 1169-1218.

Deserranno, E., 2019. Financial incentives as signals: Experimental evidence from the recruitment of village promoters in Uganda. American Economic Journal: Applied Economics 11(1), 277-317.

Diamond, P. A. 1982. Wage determination and efficiency in search equilibrium. Review of Economic Studies, 49(2), 217-227.

Faberman, R. J., \& Menzio, G. 2018. Evidence on the relationship between recruiting and the starting wage. Labour Economics, 50, 67-79.

Ferraz, C., \& Finan, F. 2009. Motivating politicians: The impacts of monetary incentives on quality and performance. National Bureau of Economic Research Working Paper No. 14906. 
Flinn, C. J. 2006. Minimum wage effects on labor market outcomes under search, matching, and endogenous contact rates. Econometrica, 74(4), 1013-1062.

Flory, J. A., Leibbrandt, A., \& List, J. A. 2015. Do competitive workplaces deter female workers? A large-scale natural field experiment on job-entry decisions. Review of Economic Studies, 82(1), 122-155.

Gee, L. K. 2019. The more you know: information effects on job application rates in a large field experiment. Management Science, 65(5), 2077-2094.

Godoy, A., \& Moen, E. R. 2011. Taking competitive search to the data. Unpublished paper.

Harrison, G.W., \& List, J.A. 2004. Field experiments. Journal of Economic Literature, 42(4), 1009-1055.

He, H., Neumark, D., \& Weng, Q. 2021. Do workers value flexible jobs? A field experiment. Journal of Labor Economics, 39 (3), 709-738.

Hedblom, D., Hickman, B. R., \& List, J. A. 2019. Toward an understanding of corporate social responsibility: Theory and field experimental evidence). National Bureau of Economic Research Working Paper No. 26222.

Holzer, H. J., Katz, L. F., \& Krueger, A. B. 1991. Job queues and wages. Quarterly Journal of Economics, 106(3), 739-768.

Horton, J. J., \& Johari, R. (2018). Buyer signaling improves matching: Evidence from a field experiment. Unpublished paper.

Hosios, Arthur J. 1990. On the efficiency of matching and related models of search and unemployment. Review of Economic Studies, 57(2), 279-298.

Ibañez, M., \& Riener, G. 2018. Sorting through affirmative action: Three field experiments in Colombia. Journal of Labor Economics, 36(2), 437-478.

Kircher, P. (2009). Efficiency of simultaneous search. Journal of Political Economy, 117(5), 861-913.

Kircher, P. (2020). Search design and online job search-new avenues for applied and experimental research. Labour Economics, 64, 101820.

Krueger, A., 1988. The determinants of queues for federal jobs. Industrial and Labor Relations Review, 41(4), 567-581.

Leibbrandt, A., \& List, J.A. 2019. Do Equal Employment Opportunity statements backfire? Evidence from a natural field experiment on job-entry Decisions. Unpublished paper, University of Chicago.

Leibbrandt, A., \& List, J.A. 2015. Do women avoid salary negotiations? Evidence from a largescale natural field experiment. Management Science, 61(9), 2016-2024.

Marinescu, I., \& Wolthoff, R. 2020. Opening the black box of the matching function: The power of words. Journal of Labor Economics, Forthcoming.

Mas, A., Amanda P. 2017. Valuing alternative work arrangements. American Economic Review 107(12), 3722-3759.

Faberman, J. R. \& Menzio, G. 2018. Evidence on the relationship between recruiting and the starting wage. Labour Economics, 50, 67-79. 
Menzio, G., Telyukova, I. A., \& Visschers, L. 2016. Directed search over the life cycle. Review of Economic Dynamics, 19, 38-62.

Moen, E. R. 1997. Competitive search equilibrium. Journal of Political Economy, 105(2), 385411.

Moen, E. R., \& Rosén, Å. 2004. Does poaching distort training? Review of Economic Studies, 71(4), 1143-1162.

Montgomery, J. D. 1991. Equilibrium wage dispersion and interindustry wage differentials. Quarterly Journal of Economics, 106(1), 163-179.

Mortensen, D. T. 1982. Property rights and efficiency in mating, racing, and related games. American Economic Review, 72(5), 968-979.

Mortensen, D. T. 1986. Job search and labor market analysis. In Ashenfelter, O., Card, D. (eds.). The Handbook of Labor Economics, Vol. 2, 849-919. Amsterdam: North-Holland.

National Bureau of Statistics of China. 2018. China Statistical Yearbook. China Statistics Press, Beijing.

Peters, M. 1984. Bertrand equilibrium with capacity constraints and restricted mobility. Econometrica, 52(5), 1117-1127.

Peters, M. 1991. Ex ante price offers in matching games non-steady states. Econometrica, 59(5), 1425-1454.

Pissarides, C. 1985. Short-run equilibrium dynamics of unemployment, vacancies, and real wages. American Economic Review, 75(4), 676-690.

Shi, S. 2002. A directed search model of inequality with heterogeneous skills and skill-biased technology. Review of Economic Studies, 69(2), 467-491.

Wright, R., Kircher, P., Julien, B., \& Guerrieri, V. 2019. Directed and competitive search: A guided tour. Journal of Economic Literature, forthcoming. 
Table 1. Applications and questionnaire completion by treatment

\begin{tabular}{lccc}
\hline Treatment & Number of applications & Number of job seekers & Application rate \\
\hline Low & 99 & 33,052 & $0.30 \%$ \\
Medium & 121 & 33,063 & $0.37 \%$ \\
High & 149 & 33,063 & $0.45 \%{ }^{* * *, \dagger}$ \\
Total & 369 & 99,178 & \\
\hline \multicolumn{1}{c}{ Treatment } & Number of questionnaires completed & Number of job seekers & Completion rate \\
\hline Low & 56 & 33,052 & $0.17 \%$ \\
Medium & 76 & 33,063 & $0.23 \%^{*}$ \\
High & 98 & 33,063 & $0.30 \%{ }^{* * *, \dagger}$ \\
Total & 230 & 99,178 & \\
\hline
\end{tabular}

Notes: Application rate is computed as the number of applications divided by the number of job seekers who were sent job ad emails and app messages. Completion rate is computed as the number of applications that completed the questionnaire divided by the number of job seekers who were sent job ad emails and app messages. Since we cannot track who successfully received the email or app message at the individual level, we use all job seekers intended to be treated as the denominator. The * symbols attached to Medium and High wage variables are for the statistical significance of the differences between the rates for High and Medium relative to Low, and the ${ }^{\dagger}$ symbols are for the statistical significance of the difference between the rates for High and Medium. One or three symbols indicates statistical significance at the $10 \%$ or $1 \%$ level respectively. 
Table 2. Random search vs. directed search

\begin{tabular}{|c|c|c|c|c|c|c|}
\hline \multirow[t]{2}{*}{ Dependent variable } & \multicolumn{3}{|c|}{ Apply or not } & \multicolumn{3}{|c|}{ Complete or not } \\
\hline & (1) & (2) & (3) & $\left(1^{\prime}\right)$ & $\left(2^{\prime}\right)$ & $\left(3^{\prime}\right)$ \\
\hline $\begin{array}{l}\text { Average application/questionnaire } \\
\text { completion rate for Low }\end{array}$ & $0.27 \mathrm{ppt}$ & $0.27 \mathrm{ppt}$ & $0.41 \mathrm{ppt}$ & $0.16 \mathrm{ppt}$ & $0.16 \mathrm{ppt}$ & $0.25 \mathrm{ppt}$ \\
\hline $\begin{array}{l}\text { Percentage increase for Medium } \\
\text { relative to Low average }\end{array}$ & $14.43 \%$ & $11.70 \%$ & $11.40 \%$ & $32.06 \%$ & $26.21 \%$ & $20.69 \%{ }^{*}$ \\
\hline $\begin{array}{l}\text { Percentage increase for High } \\
\text { relative to Low average }\end{array}$ & $49.97 \%{ }^{* * *}$ & $42.75 \%{ }^{* * *}$ & $38.32 \%{ }^{* * *}$ & $71.67 \%{ }^{* * *}$ & $60.98 \%{ }^{* * *}$ & $53.55 \%{ }^{* * *}$ \\
\hline $\begin{array}{l}\text { Average application/questionnaire } \\
\text { completion rate for Medium }\end{array}$ & $0.31 \mathrm{ppt}$ & $0.31 \mathrm{ppt}$ & $0.52 \mathrm{ppt}$ & $0.21 \mathrm{ppt}$ & $0.21 \mathrm{ppt}$ & $0.36 \mathrm{ppt}$ \\
\hline $\begin{array}{l}\text { Percentage increase for High } \\
\text { relative to Medium average }\end{array}$ & $31.06 \%{ }^{++}$ & $27.14 \%^{++}$ & $20.97 \% \%^{++}$ & $30.00 \%^{\dagger}$ & $26.33 \%^{\dagger}$ & $22.78 \%^{+\dagger}$ \\
\hline Medium & $\begin{array}{c}0.0004 \\
(0.0004)\end{array}$ & $\begin{array}{c}0.0003 \\
(0.0004)\end{array}$ & $\begin{array}{c}0.0005 \\
(0.0004)\end{array}$ & $\begin{array}{c}0.0005 \\
(0.0003)\end{array}$ & $\begin{array}{c}0.0004 \\
(0.0003)\end{array}$ & $\begin{array}{l}0.0005^{*} \\
(0.0003)\end{array}$ \\
\hline High & $\begin{array}{c}0.0014^{* *,+\dagger}+ \\
(0.0005)\end{array}$ & $\begin{array}{c}0.0012^{* * *,+\dagger} \\
(0.0004)\end{array}$ & $\begin{array}{c}0.0016^{* *,+\dagger} \\
(0.0004)\end{array}$ & $\begin{array}{c}0.0011^{* * *, \dagger}+ \\
(0.0004)\end{array}$ & $\begin{array}{c}0.0010^{* * *, \dagger} \\
(0.0003)\end{array}$ & $\begin{array}{c}0.0013^{* * *,+\dagger} \\
(0.0004)\end{array}$ \\
\hline Job characteristics & No & Yes & Yes & No & Yes & Yes \\
\hline Job seeker characteristics & No & No & Yes & No & No & Yes \\
\hline Number of job seekers & 99,146 & 99,146 & 58,151 & 99,146 & 99,146 & 58,151 \\
\hline Wald $\chi^{2}$ & $9.71^{* * *}$ & $75.84^{* * *}$ & $377.91^{* * *}$ & $10.05^{* * *}$ & $57.87^{* * * *}$ & $274.06^{* * *}$ \\
\hline
\end{tabular}

Notes: The table reports marginal effects from a probit model in the bottom panel, and implied percentage changes in the upper panel. The dependent variable is indicated in column headings. The sample includes only job seekers who were sent job ad emails and app messages. We exclude applications made to job positions other than those applicants were sent. Job characteristics include job flexibility and job position dummy variables, and job seeker characteristics include gender, marital status, age and its square, highest educational degree in category, years of work experience and its square, overseas work/study experience, current work status, job tenure and its square, Beijing Hukou, type of job sought (full-time, parttime, or intern), and expect to work in Beijing. Job seekers with missing or inconsistent data on individual characteristics are excluded. Robust standard errors allowing for heteroskedasticity are reported in parentheses. The * symbols attached to Medium and High wage variables in the lower panel and to percentage increase in the upper panel are for the statistical significance of the High and Medium relative to Low estimates, and the ${ }^{\dagger}$ symbols are for the statistical significance of the High relative to the Medium estimates. One, two, or three symbols indicates statistical significance at the $10 \%, 5 \%$, or $1 \%$ level, respectively. (There were 41 applications made by 32 applicants to job positions other than those they were sent in the job ad emails and app messages. This explains the decrease in the total number of job seekers from 99,178 in Table 1 to 99,146 in columns (1), (2), (1'), and (2') in Table 2, and explains the decrease in the application and questionnaire completion rates, which occurs for the Low and Medium wage offers, from Table 1 to the same columns in Table 2.) 
Table 3. Random search vs. directed search conditional on RW no more than 15,000 CNY

\begin{tabular}{|c|c|c|c|c|}
\hline Sample restriction & Less $\mathrm{I}$ & ctive & More 1 & rictive \\
\hline Dependent variable & $\begin{array}{c}\text { Apply or not } \\
\text { (1) }\end{array}$ & $\begin{array}{c}\text { Complete or } \\
\text { not } \\
\left(1^{\prime}\right)\end{array}$ & $\begin{array}{l}\text { Apply or not } \\
\text { (2) }\end{array}$ & $\begin{array}{c}\text { Complete or } \\
\text { not } \\
(2 ')\end{array}$ \\
\hline $\begin{array}{l}\text { Average application/questionnaire } \\
\text { completion rate for Low }\end{array}$ & $0.40 \mathrm{ppt}$ & $0.25 \mathrm{ppt}$ & & \\
\hline $\begin{array}{l}\text { Percentage increase for Medium relative to } \\
\text { Low average }\end{array}$ & $3.69 \%$ & $10.65 \%$ & & \\
\hline $\begin{array}{l}\text { Percentage increase for High relative to Low } \\
\text { average }\end{array}$ & $24.90 \%{ }^{* *}$ & $36.37 \%{ }^{* *}$ & & \\
\hline $\begin{array}{l}\text { Average application/questionnaire } \\
\text { completion rate for Medium }\end{array}$ & $0.45 \mathrm{ppt}$ & $0.31 \mathrm{ppt}$ & $0.45 p p t$ & 0.31ppt \\
\hline $\begin{array}{l}\text { Percentage increase for High relative to } \\
\text { Medium average }\end{array}$ & $18.61 \%^{\dagger}$ & $20.67 \%^{\dagger}$ & $14.81 \%^{\dagger}$ & $16.74 \%$ \\
\hline Medium & $\begin{array}{c}0.0001 \\
(0.0004)\end{array}$ & $\begin{array}{c}0.0003 \\
(0.0003)\end{array}$ & & \\
\hline High & $\begin{array}{c}0.0010^{* *, \dagger} \\
(0.0005)\end{array}$ & $\begin{array}{l}0.0009^{* *, \dagger} \\
(0.0004)\end{array}$ & $\begin{array}{c}0.0007^{\dagger} \\
(0.0004)\end{array}$ & $\begin{array}{c}0.0005 \\
(0.0003)\end{array}$ \\
\hline Job characteristics & Yes & Yes & Yes & Yes \\
\hline Job seeker characteristics & Yes & Yes & Yes & Yes \\
\hline Number of job seekers & 50,641 & 50,641 & 33,708 & 33,708 \\
\hline Wald $\chi^{2}$ & $310.84^{* * *}$ & $238.51^{* * *}$ & $259.81^{* * *}$ & $198.35^{* * *}$ \\
\hline
\end{tabular}

Notes: The table reports marginal effects from a probit model in the bottom panel, and implied percentage changes in the top panel. The sample restriction and dependent variable are indicated in column headings. The RW is measured by the current/most recent wage. The sample in all models is restricted to job seekers who had RW no more than 15,000 CNY. In addition, the "less restrictive" sample includes job seekers who were sent Low, Medium, or High wage offers, whereas the "more restrictive" sample only includes job seekers who were sent Medium or High wage offers. All models include control variables for job and job seeker characteristics as in columns (3) and (3') of Table 2. See also notes to Table 2. 
Table 4. Summary statistics of observed characteristics related to quality for job seekers by $\mathrm{RW}$ range

\begin{tabular}{|c|c|c|c|c|c|}
\hline $\begin{array}{l}\text { Current/most recent job's wage } \\
\text { range }\end{array}$ & $2000<$ RW $\leq 4000$ & $4000<\mathrm{RW} \leq 6000$ & $6000<\mathrm{RW} \leq 8000$ & $8000<\mathrm{RW} \leq 10000$ & $10000<\mathrm{RW} \leq 15000$ \\
\hline \multirow[t]{3}{*}{ Currently employed (percent) } & 0.18 & 0.35 & 0.43 & 0.47 & 0.52 \\
\hline & $(0.38)$ & $(0.48)$ & $(0.49)$ & $(0.50)$ & $(0.50)$ \\
\hline & [0.004] & [0.004] & [0.005] & [0.01] & {$[0.01]$} \\
\hline \multirow[t]{3}{*}{ Tenure (year) } & 0.58 & 0.88 & 1.15 & 1.39 & 1.62 \\
\hline & $(1.78)$ & $(1.93)$ & $(2.12)$ & $(2.38)$ & $(2.62)$ \\
\hline & {$[0.02]$} & {$[0.02]$} & [0.02] & {$[0.03]$} & {$[0.03]$} \\
\hline \multirow[t]{3}{*}{ Work experience (year) } & 4.24 & 4.42 & 5.23 & 6.17 & 6.99 \\
\hline & $(3.74)$ & $(3.78)$ & $(4.00)$ & $(4.39)$ & $(4.48)$ \\
\hline & [0.04] & {$[0.03]$} & {$[0.04]$} & {$[0.05]$} & {$[0.05]$} \\
\hline \multicolumn{6}{|l|}{ Education } \\
\hline \multirow{3}{*}{ College (percent) } & 0.37 & 0.39 & 0.31 & 0.26 & 0.20 \\
\hline & $(0.48)$ & $(0.49)$ & $(0.46)$ & $(0.44)$ & $(0.40)$ \\
\hline & {$[0.01]$} & [0.004] & [0.004] & {$[0.01]$} & [0.005] \\
\hline \multirow[t]{3}{*}{ Bachelor (percent) } & 0.54 & 0.57 & 0.61 & 0.61 & 0.64 \\
\hline & $(0.50)$ & $(0.50)$ & $(0.49)$ & $(0.49)$ & $(0.48)$ \\
\hline & {$[0.01]$} & [0.004] & [0.005] & {$[0.01]$} & {$[0.01]$} \\
\hline \multirow[t]{3}{*}{ Master or above (percent) } & 0.09 & 0.04 & 0.08 & 0.13 & 0.16 \\
\hline & $(0.29)$ & $(0.20)$ & $(0.27)$ & $(0.34)$ & $(0.37)$ \\
\hline & [0.003] & [0.002] & [0.003] & {$[0.004]$} & {$[0.004]$} \\
\hline \multirow[t]{3}{*}{ IT-related industry (percent) } & 0.20 & 0.23 & 0.30 & 0.33 & 0.40 \\
\hline & $(0.40)$ & $(0.42)$ & $(0.46)$ & $(0.47)$ & $(0.49)$ \\
\hline & [0.005] & [0.004] & [0.004] & {$[0.01]$} & {$[0.01]$} \\
\hline Number of job seekers & 7,372 & 13,428 & 11,036 & 7,621 & 7,315 \\
\hline
\end{tabular}

Notes: Statistics in parentheses (brackets) are the standard deviations (standard errors of means) of the indicated characteristics for job seekers in the indicated RW range. "College" refers to the tertiary education degree that requires two or three years to complete. 
Table 5. Random search vs. directed search by RW range conditional on RW no more than 15,000 CNY

\begin{tabular}{|c|c|c|c|c|}
\hline \multirow{2}{*}{$\begin{array}{l}\text { Sample restriction } \\
\text { Dependent variable }\end{array}$} & \multicolumn{2}{|c|}{ Less restrictive } & \multicolumn{2}{|c|}{ More restrictive } \\
\hline & $\begin{array}{l}\text { Apply or not } \\
\text { (1) }\end{array}$ & $\begin{array}{c}\text { Complete or not } \\
\left(1^{\prime}\right)\end{array}$ & $\begin{array}{l}\text { Apply or not } \\
\text { (2) }\end{array}$ & $\begin{array}{c}\text { Complete or not } \\
\left(2^{\prime}\right)\end{array}$ \\
\hline \multicolumn{5}{|l|}{$2,000<\mathrm{RW} \leq 15,000$} \\
\hline Medium & $\begin{array}{c}0.0001 \\
(0.0004)\end{array}$ & $\begin{array}{c}0.0004 \\
(0.0003)\end{array}$ & & \\
\hline High & $\begin{array}{c}0.0011^{* *,+\dagger} \\
(0.0005)\end{array}$ & $\begin{array}{l}0.0010^{*+* *} \\
(0.0004)\end{array}$ & $\begin{array}{l}0.0008^{*} \\
(0.0004)\end{array}$ & $\begin{array}{c}0.0005 \\
(0.0003)\end{array}$ \\
\hline Number of job seekers & 46,772 & 46,772 & 31,134 & 31,134 \\
\hline \multicolumn{5}{|l|}{$4,000<\mathrm{RW} \leq 15,000$} \\
\hline Medium & $\begin{array}{l}0.00002 \\
(0.0005)\end{array}$ & $\begin{array}{c}0.0003 \\
(0.0003)\end{array}$ & & \\
\hline High & $\begin{array}{c}0.0011^{* *, \dagger} \\
(0.0006)\end{array}$ & $\begin{array}{c}0.0010^{* *, \dagger}+ \\
(0.0004)\end{array}$ & $\begin{array}{l}0.0008^{*} \\
(0.0005)\end{array}$ & $\begin{array}{l}0.0006^{*} \\
(0.0004)\end{array}$ \\
\hline Number of job seekers & 39,400 & 39,400 & 26,165 & 26,165 \\
\hline \multicolumn{5}{|l|}{$6,000<\mathrm{RW} \leq 15,000$} \\
\hline Medium & $\begin{array}{l}-0.00004 \\
(0.0007)\end{array}$ & $\begin{array}{c}0.0001 \\
(0.0005)\end{array}$ & & \\
\hline High & $\begin{array}{c}0.0016^{* *,+\dagger} \\
(0.0008)\end{array}$ & $\begin{array}{c}0.0014^{*,+,+}+ \\
(0.0006)\end{array}$ & $\begin{array}{l}0.0013^{*} \\
(0.0006)\end{array}$ & $\begin{array}{l}0.0010^{*} \\
(0.0005)\end{array}$ \\
\hline Number of job seekers & 25,922 & 25,922 & 17,243 & 17,243 \\
\hline \multicolumn{5}{|l|}{$8,000<\mathrm{RW} \leq 15,000$} \\
\hline Medium & $\begin{array}{l}0.00002 \\
(0.0011)\end{array}$ & $\begin{array}{c}0.0005 \\
(0.0007)\end{array}$ & & \\
\hline High & $\begin{array}{c}0.0018 \\
(0.0012)\end{array}$ & $\begin{array}{c}0.0020^{* *, \dagger} \\
(0.0009)\end{array}$ & $\begin{array}{c}0.0013 \\
(0.0010)\end{array}$ & $\begin{array}{c}0.0012 \\
(0.0007)\end{array}$ \\
\hline Number of job seekers & 14,794 & 14,794 & 9,825 & 9,825 \\
\hline Medium & $\begin{array}{c}0.0003 \\
(0.0016)\end{array}$ & $\begin{array}{c}0.0008 \\
(0.0009)\end{array}$ & & \\
\hline High & $\begin{array}{c}0.0040^{* *,+} \\
(0.0020)\end{array}$ & $\begin{array}{l}0.0032^{* *, \dagger} \\
(0.0014)\end{array}$ & $\begin{array}{c}0.0030^{*} \\
(0.0018)\end{array}$ & $\begin{array}{c}0.0021 \\
(0.0013)\end{array}$ \\
\hline Number of job seekers & 7,261 & 7,261 & 4,839 & 4,839 \\
\hline \multicolumn{5}{|c|}{$\begin{array}{l}\text { Notes: The table reports marginal effects from probit models. The sample restriction and dependent variable are } \\
\text { indicated in column headings. The RW is measured by the current/most recent wage. The sample in all models } \\
\text { is restricted to job seekers who had RW no more than } 15,000 \text { CNY. In addition, the "less restrictive" sample } \\
\text { includes job seekers who were sent Low, Medium, or High wage offers, whereas the "more restrictive" sample } \\
\text { only includes job seekers who were sent Medium or High wage offers. Each panel from the top to the bottom } \\
\text { increases the RW lower limit. All models include control variables for job and job seeker characteristics as in } \\
\text { columns (3) and (3') of Table 2. See also notes to Table 2. }\end{array}$} \\
\hline
\end{tabular}


Table 6. Random search vs. directed search by $\mathrm{RW}$ range conditional on $\mathrm{RW}$ no more than 15,000 CNY, Differential Effects of RW by Wage Offer

\begin{tabular}{lcccc}
\hline $\begin{array}{l}\text { Sample restriction } \\
\text { Dependent variable }\end{array}$ & \multicolumn{2}{c}{ Less restrictive } & \multicolumn{2}{c}{ More restrictive } \\
& Apply or & $\begin{array}{c}\text { Complete or } \\
\text { not }\end{array}$ & $\begin{array}{c}\text { Apply or } \\
\text { not }\end{array}$ & $\begin{array}{c}\text { Complete or } \\
\text { not }\end{array}$ \\
$\begin{array}{l}\text { Effect of } R \text { W on marginal effect of higher } \\
\text { wage offers (evaluated at the mean of RW): }\end{array}$ & $(1)$ & $(2)$ & $\left(1^{\prime}\right)$ & $\left(2^{\prime}\right)$ \\
\hline Medium vs. Low & -0.00001 & 0.00007 & & \\
& $(0.00011)$ & $(0.00008)$ & & \\
High vs. Low & 0.00017 & $0.00021^{* *}$ & & \\
& $(0.00011)$ & $(0.00009)$ & & 0.00012 \\
High vs. Medium & 0.00018 & 0.00015 & 0.00014 & $(0.00008)$ \\
\hline
\end{tabular}

Notes: The table reports marginal effects from probit models with interactions between the wage offer dummy variables and the RW midpoint, with the effect of the RW on marginal effect of higher wage offers evaluated at the mean of the RW midpoint. The sample restriction and dependent variable are indicated in column headings. The RW is measured by the current/most recent wage. The sample in all models is restricted to job seekers who had RW no more than 15,000 CNY. In addition, the "less restrictive" sample includes job seekers who were sent Low, Medium, or High wage offers, whereas the "more restrictive" sample only includes job seekers who were sent Medium or High wage offers. All models include control variables for job and job seeker characteristics as in columns (3) and (3') of Table 2. See also notes to Table 2. 


\title{
Online Appendix for: \\ “I Still Haven't Found What I'm Looking For": Evidence of Directed Search from a Field Experiment
}

\author{
Haoran He, David Neumark, Qian Weng
}

\section{Appendix A. Fringe benefits as a Mechanism to Attract Applicants}

Employers may use other mechanisms to attract applicants, besides wages. In this appendix, we present evidence on one possible such mechanism - fringe benefits. The literature has documented a variety of mechanisms that could direct workers' job search, such as the information on the number of competing applicants (Gee, 2019), affirmative action statements (Ibanez and Riener, 2018; Leibbrandt and List, 2019), and job characteristics such as wage negotiation opportunity (Leibbrandt and List, 2015), competitiveness (Flory et al., 2015), and job flexibility (He et al., 2021; Mas and Pallais 2017). We focus on fringe benefits, since these are important amenities that employers can offer employees, on which we have data. Employers can list up to eight pre-specified fringe benefits in a job ad. We rely on the non-experimental data discussed in footnote 19 to do the analysis, i.e., 342,152 full-time job ads posted for the five occupations studied in our experiment (software, finance, personnel (human resources, or HR), marketing, and sales management), for jobs located in Beijing, between November 20, 2017 and March 2, 2018. We also restrict to jobs advertised with wage offers.

Table A1 reports summary statistics for the fringe benefits offered. We see that a large variety of fringe benefits are offered, and the proportion of jobs offering them vary a great deal (as reflected in the standard deviations).

We then estimate the relationship between the number of applications and fringe benefits offered, conditional on wage offered (the midpoint of the range). Table A2 reports regression results. For brevity we report only the estimated effects of fringe benefits (the table notes explain the other controls). We see that many fringe benefits are positively and statistically significantly associated with the number of applications, suggesting that this is another mechanism employers use to attract applicants. Of course, in non-experimental data we have to be cautious about interpreting these kinds of findings as causal, since variation in fringe benefits may be correlated with other features of jobs. However, in our experimental design there is no concern that our results are driven by variation in fringe benefits (which are held fixed), or by the job flexibility conditions that can vary (because the assignment of wage offer is random within each job flexibility condition). 
Table A1. Summary statistics for fringe benefit variables for analysis of employer job ads

\begin{tabular}{lccc}
\hline Variable & Mean & Std. dev. & $\mathrm{N}$ \\
\hline Number of applications & 290.01 & 1046.59 & 342,152 \\
\hline Fringe benefits & & & \\
\hline Job flexibility & 0.21 & 0.41 & 326,100 \\
14-month salary & 0.02 & 0.14 & 326,100 \\
No overtime work & 0.05 & 0.21 & 326,100 \\
Five social insurance and one housing fund & 0.79 & 0.40 & 326,100 \\
Transportation allowance & 0.25 & 0.43 & 326,100 \\
Housing allowance & 0.07 & 0.25 & 326,100 \\
Gym card & 0.02 & 0.13 & 326,100 \\
Interest-free mortgage & 0.00 & 0.04 & 326,100 \\
Free shuttle bus & 0.05 & 0.22 & 326,100 \\
Attendance bonus & 0.20 & 0.40 & 326,100 \\
Start-up company & 0.05 & 0.21 & 326,100 \\
Overtime allowance & 0.13 & 0.34 & 326,100 \\
Free dormitory & 0.08 & 0.27 & 326,100 \\
Free meals & 0.06 & 0.24 & 326,100 \\
Staff travel & 0.34 & 0.48 & 326,100 \\
Weekend off & 0.00 & 0.02 & 326,100 \\
Regular health examination & 0.31 & 0.46 & 326,100 \\
Paid annual leave & 0.56 & 0.50 & 326,100 \\
Double pay at year end & 0.26 & 0.44 & 326,100 \\
Year-end dividend & 0.12 & 0.33 & 326,100 \\
No probation period & 0.01 & 0.09 & 326,100 \\
Multiple pay raises per year & 0.06 & 0.23 & 326,100 \\
Performance-based bonus & 0.51 & 0.50 & 326,100 \\
Stocks and options & 0.06 & 0.24 & 326,100 \\
Holiday benefits & 0.55 & 0.50 & 326,100 \\
Supplementary medical insurance & 0.20 & 0.40 & 326,100 \\
Communication allowance & 0.20 & 0.40 & 326,100 \\
Heating allowance & 0.02 & 0.14 & 326,100 \\
Meal allowance & 0.36 & 0.48 & 326,100 \\
High-temperature allowance & 0.04 & 0.19 & 326,100 \\
\hline Notes: After dropping observatons & & & \\
\hline
\end{tabular}

Notes: After dropping observations with missing data, for the sample available for the regression analysis including all of these variables and other control variables included in Table A2, $\mathrm{N}=310,738$ (from a total sample of 342,152 observations). 
Appendix Table A2. Relationship between number of applications and fringe benefits

\begin{tabular}{|c|c|c|}
\hline Dependent variable: Number of applications & (1) & $(2)$ \\
\hline & OLS & $\begin{array}{l}\text { Establishment fixed } \\
\text { effects }\end{array}$ \\
\hline Job flexibility & $\begin{array}{c}-10.862 \\
(9.325)\end{array}$ & $\begin{array}{c}24.086^{* *} \\
(9.687)\end{array}$ \\
\hline 14-month salary & $\begin{array}{c}-168.350^{* * *} \\
(27.101)\end{array}$ & $\begin{array}{c}-83.507^{* * *} \\
(17.731)\end{array}$ \\
\hline No overtime work & $\begin{array}{c}-83.373^{* * * *} \\
(7.729)\end{array}$ & $\begin{array}{c}-53.381^{* * *} \\
(9.111)\end{array}$ \\
\hline Five social insurance and one housing fund & $\begin{array}{l}-0.984 \\
(7.614)\end{array}$ & $\begin{array}{l}-0.345 \\
(8.335)\end{array}$ \\
\hline Transportation allowance & $\begin{array}{l}4.948 \\
(9.627)\end{array}$ & $\begin{array}{c}6.893 \\
(8.760)\end{array}$ \\
\hline Housing allowance & $\begin{array}{c}-95.023^{* * * *} \\
(11.614)\end{array}$ & $\begin{array}{l}-23.873^{*} \\
(12.230)\end{array}$ \\
\hline Gym card & $\begin{array}{c}-89.667^{* * *} \\
(17.586)\end{array}$ & $\begin{array}{c}-114.629^{* * *} \\
(22.080)\end{array}$ \\
\hline Interest-free mortgage & $\begin{array}{l}26.127 \\
(53.595)\end{array}$ & $\begin{array}{c}13.495 \\
(55.300)\end{array}$ \\
\hline Free shuttle bus & $\begin{array}{l}-63.164^{* * * *} \\
(15.555)\end{array}$ & $\begin{array}{c}4.364 \\
(12.418)\end{array}$ \\
\hline Attendance bonus & $\begin{array}{c}-34.268^{* * *} \\
(9.195)\end{array}$ & $\begin{array}{c}-1.612 \\
(10.693)\end{array}$ \\
\hline Start-up company & $\begin{array}{l}-138.837^{* * *} \\
(9.763)\end{array}$ & $\begin{array}{c}-148.012^{* * *} \\
(12.632)\end{array}$ \\
\hline Overtime allowance & $\begin{array}{c}9.533 \\
(12.633)\end{array}$ & $\begin{array}{c}29.667^{* * *} \\
(11.395)\end{array}$ \\
\hline Free dormitory & $\begin{array}{l}-89.504^{* * *} \\
(19.280)\end{array}$ & $\begin{array}{c}-3.417 \\
(15.071)\end{array}$ \\
\hline Free meals & $\begin{array}{l}47.158^{* * * *+} \\
(14.675)\end{array}$ & $\begin{array}{l}17.320 \\
(14.661)\end{array}$ \\
\hline Staff travel & $\begin{array}{l}7.770 \\
(7.298)\end{array}$ & $\begin{array}{l}26.404^{* * * *} \\
(7.870)\end{array}$ \\
\hline Weekend off & $\begin{array}{l}124.193 \\
(99.868)\end{array}$ & $\begin{array}{c}38.148 \\
(90.703)\end{array}$ \\
\hline Regular health examination & $\begin{array}{c}23.106^{* * *} \\
(7.983)\end{array}$ & $\begin{array}{l}12.200 \\
(9.460)\end{array}$ \\
\hline Paid annual leave & $\begin{array}{c}39.464^{* * *} \\
(6.740)\end{array}$ & $\begin{array}{l}14.734^{* * *} \\
(6.922)\end{array}$ \\
\hline Double pay at year end & $\begin{array}{l}-14.476 \\
(8.973)\end{array}$ & $\begin{array}{l}21.588^{* *} \\
(9.359)\end{array}$ \\
\hline Year-end dividend & $\begin{array}{l}-26.069^{* *} \\
(10.528)\end{array}$ & $\begin{array}{l}16.450^{*} \\
(9.395)\end{array}$ \\
\hline No probation period & $\begin{array}{l}51.823^{* *} \\
(21.001)\end{array}$ & $\begin{array}{c}33.498 \\
(21.268)\end{array}$ \\
\hline Multiple pay raises per year & $\begin{array}{l}-95.092^{* * *} \\
(10.387)\end{array}$ & $\begin{array}{c}-70.481^{* * *} \\
(10.989)\end{array}$ \\
\hline Performance-based bonus & $\begin{array}{l}18.842^{* * * *} \\
(7.087)\end{array}$ & $\begin{array}{l}21.325^{* * *} \\
(6.899)\end{array}$ \\
\hline Stocks and options & $\begin{array}{l}59.495^{* * * *} \\
(19.388)\end{array}$ & $\begin{array}{l}36.771^{* *} \\
(17.164)\end{array}$ \\
\hline
\end{tabular}


Holiday benefits

Communication allowance

Heating allowance

Meal allowance

Number of job seekers 310,738

Notes: The estimators of the models are indicated in the column heading. The table reports only the estimated coefficients of fringe benefits; however, the table includes controls for job and establishment characteristics, including: log of the midpoint of offered monthly wage; required educational degree levels; required years of work experience ranges; number of vacancies; occupation indicators; establishment size indicators; establishment ownership indicators; industry indicators. The sample is a little smaller than the number of observations with fringe benefits in Table A1 because of missing data on control variables. Robust standard errors allowing for heteroskedasticity and correlation within establishments are reported in parentheses. ${ }^{*},{ }^{* *}$ or ${ }^{* * *}$ indicate statistical significance at the $10 \%$, $5 \%$, or $1 \%$ levels, respectively. 


\section{Appendix Figure B1. Distribution of the Lower and Upper Limits of Wage Ranges}
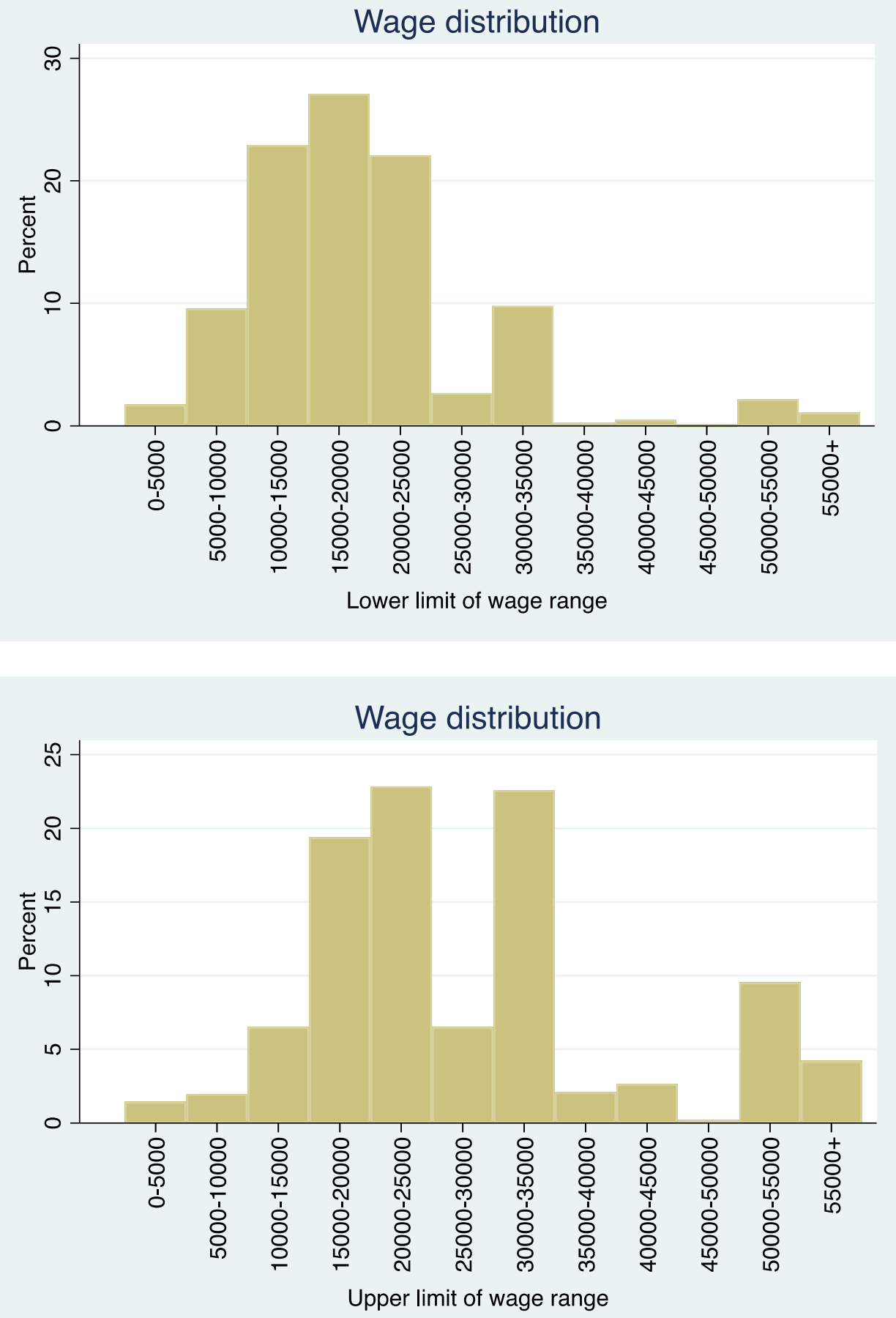

Notes: These ranges were derived from the distribution of the wage ranges of over 8,000 real job ads collected from the job board a few months before our experiment, recruiting for the five experimental occupations, and requiring at least college education and at least 5-10 years of work experience. 


\section{Appendix C. Examples of Job Ad Email and App Message}

\section{Email subject line:}

Job recommendation: Financial Executive [with both flexible work time and place/monthly wage: $15-20 \mathrm{~K}]$

\section{Email content}

Hi! Your qualifications match our [Financial Executive] position well! We hence recommend you this job! See below for more information.

\section{Financial Executive (15000-20000 Yuan/month)}

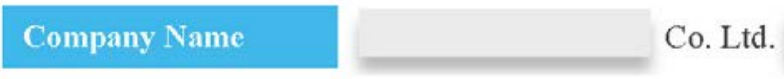

\section{Place of Work Beijing}

\section{Work Arrangements}

The first month: working in the office from 9 am to $6 \mathrm{pm}$ with one hour lunch break from Monday to Friday.

Weekend off.

After one month: working in the office from 9 am to $6 \mathrm{pm}$ with one hour lunch break on Monday; work at any places via logging into the company's online working system for 8 hours starting between 7 am and 10 am and ending between $4 \mathrm{pm}$ and $7 \mathrm{pm}$ from Tuesday to Friday. Weekend off.

\section{Job Responsibility}

1. Formulate and implement monthly, quarterly and annual financial budget, and produce corresponding financial report.

2. Control operation budget, plan and declare tax; manage capital allocation, cost and financial accounting and financial analysis.

3. Formulate, maintain and improve the company's financial management system and work procedures ...... [More]

Please note that the deadline for application is 9 am on January 24, 2018 (Wednesday).

\section{Learn more about the job}

\section{App Message}

Find your dream job here!

Click to check the job designated for you: Financial Executive [with both flexible work time and place/monthly wage: $15-20 \mathrm{~K}]$ 


\section{Appendix D. A Job Ad on the Employer's Webpage Posted in the Experiment}

Financial Executive [with both flexible work time and place]

\begin{tabular}{|l|l|l|l|}
\hline \multicolumn{2}{|c}{ Co. Ltd. } \\
\hline Five social insurance and one housing fund & Double pay at year end & Performance-based bonus \\
\hline Communication allowance & Paid annual leave & Flexible working conditions \\
\hline Regular health examination & Holiday benefits \\
\hline
\end{tabular}

Monthly salary: Negotiable

Publish date: In recruitment

Place of work: Haidian District, Beijing

Work experience required: 5 -10 years

Job type: Full time

Number of vacancies: 2

Educational degree required: College

Occupation type: Financial officer

Job Description Company Introduction

Job Responsibility

1. Formulate and implement monthly, quarterly and annual financial budget, and produce corresponding financial report.

2. Control operation budget, plan and declare tax; manage capital allocation, cost and financial accounting and financial analysis.

3. Formulate, maintain and improve the company's financial management system and work procedures; establish an accountable financial accounting system and financial monitoring system to achieve effective internal control.

4. Establish and maintain good relations with industrial and commercial institutions, tax bureaus, banks, etc.

Job Requirements

1. At least 5 years relevant work experience; strong in work ethics, teamwork spirit, sense of responsibility, self-motivation and communication skills.

2. Serious working, dedicated to details, fast-learning, and pressure taking ability are valued.

3. Have comprehensive accounting knowledge, familiar with daily financial management procedures, financial and legislative regulations and common financial softwares.

4. Good at cost management, risk control and financial analysis; good management and problem-solving capabilities.

\section{Work arrangements}

The first month: work in the office from 9 AM to 6 PM for 8 hours from Monday to Friday. Weekend off.

After one month: work in the office from $9 \mathrm{AM}$ to $6 \mathrm{PM}$ for 8 hours on Monday; work at wherever you like via logging into the company's online working system for 8 hours starting between $7 \mathrm{AM}$ and $10 \mathrm{AM}$ and ending between 4 PM and 7 PM from Tuesday to Friday. Weekend off.

Inquiring Email:

Please note that the deadline for applying this job is 9 am on January 24, 2018 (Wednesday).

After reviewing your qualifications, the company will invite you for an interview, so stay tuned!

Welcome to joining us!

Work address

Apply Now 


\section{Appendix E. Additional Tables}

Appendix Table E1. Pairwise randomization tests between treatments

\begin{tabular}{|c|c|c|c|c|c|c|c|c|c|}
\hline \multirow[b]{2}{*}{ Variable } & \multicolumn{3}{|c|}{$\begin{array}{l}\text { Low } \\
\text { (1) }\end{array}$} & \multicolumn{3}{|c|}{$\begin{array}{l}\text { Medium } \\
\text { (2) }\end{array}$} & \multicolumn{3}{|c|}{$\begin{array}{c}\text { High } \\
\text { (3) }\end{array}$} \\
\hline & Obs. & Mean & Std. Dev. & Obs. & Mean & Std. Dev. & Obs. & Mean & Std. Dev. \\
\hline Female (proportion) & 32,492 & 0.54 & 0.50 & 32,486 & 0.54 & 0.50 & 32,566 & 0.54 & 0.50 \\
\hline Married (proportion) & 19,600 & 0.58 & 0.49 & 19,537 & 0.59 & 0.49 & 19,505 & 0.58 & 0.49 \\
\hline Age & 32,492 & 29.60 & 5.49 & 32,486 & 29.58 & 5.42 & 32,566 & 29.57 & 5.41 \\
\hline College (proportion) & 32,492 & 0.26 & 0.44 & 32,486 & 0.26 & 0.44 & 32,566 & 0.26 & 0.44 \\
\hline Bachelor (proportion) & 32,492 & 0.61 & 0.49 & 32,486 & 0.62 & 0.49 & 32,566 & 0.61 & 0.49 \\
\hline Master or above (proportion) & 32,492 & 0.12 & 0.33 & 32,486 & 0.13 & 0.33 & 32,566 & 0.12 & 0.33 \\
\hline Work experience & 32,492 & 7.03 & 4.95 & 32,486 & 6.97 & 4.87 & 32,566 & 6.98 & 4.88 \\
\hline Overseas studying or work experience (proportion) & 32,492 & 0.06 & 0.23 & 32,486 & 0.05 & 0.23 & 32,566 & 0.05 & 0.23 \\
\hline Currently employed & 32,220 & 0.39 & 0.49 & 32,236 & 0.38 & 0.49 & 32,301 & 0.38 & 0.49 \\
\hline Tenure & 32,220 & 1.34 & 2.66 & 32,236 & 1.35 & 2.66 & 32,301 & 1.33 & 2.64 \\
\hline Beijing Hukou (proportion) & 32,380 & 0.37 & 0.48 & 32,361 & 0.37 & 0.48 & 32,453 & 0.37 & 0.48 \\
\hline Expect to work full-time (proportion) & 32,472 & 0.97 & 0.16 & 32,468 & 0.97 & 0.16 & 32,550 & 0.97 & 0.16 \\
\hline Expect to work part-time (proportion) & 32,472 & 0.01 & 0.12 & 32,468 & 0.01 & 0.12 & 32,550 & 0.01 & 0.12 \\
\hline Expect to work as an intern (proportion) & 32,472 & 0.01 & 0.11 & 32,468 & 0.01 & 0.11 & 32,550 & 0.01 & 0.12 \\
\hline Expect to work in Beijing (proportion) & 32,433 & 0.92 & 0.27 & 32,440 & 0.92 & 0.27 & 32,521 & 0.92 & 0.27 \\
\hline Generic wage expectation midpoint & 26,790 & 10983.15 & 8585.36 & 26,721 & 11020.30 & 8736.60 & 26,890 & 11014.04 & 8729.20 \\
\hline Current/most recent job’s wage midpoint & 30,956 & 9553.92 & 8067.14 & 30,907 & 9585.71 & 8226.35 & 30,996 & 9543.86 & 8109.58 \\
\hline
\end{tabular}

Notes: The sample for each individual characteristic is limited to non-missing observations after eliminating those with inconsistent dates of events. 
Appendix Table E2. Applications and questionnaire completion by treatment

\begin{tabular}{lcc}
\hline Treatment & $\begin{array}{c}\text { Conditional } \\
\text { completion rate }\end{array}$ & $\begin{array}{c}\text { Correlation between application } \\
\text { and questionnaire completion }\end{array}$ \\
\hline Low & $56.57 \%$ & $0.7516^{* * *}$ \\
Medium & $62.81 \%$ & $0.7920^{* * *}$ \\
High & $65.77 \%$ & $0.8104^{* * *}$ \\
Total & $62.33 \%$ & $0.7889^{* * *}$ \\
\hline
\end{tabular}

Notes: Questionnaire completion rate conditional on applying is computed as the number of applications that completed the questionnaire divided by the number of applications made. The sample used here includes in total 99,187 observations, 9 more observations than the number of job seekers listed in column (2) of Table 1, since 8 applicants made multiple applications, which are included in the number of applications and the number of questionnaires completed in column (1) of Table $1 .{ }^{* * *}$ indicates statistical significance at the $1 \%$ level. 
Appendix Table E3. Summary statistics of regression variables

\begin{tabular}{|c|c|c|c|c|}
\hline Variable & Mean & Std. Dev. & $\mathrm{N}$ & $\%$ missing values \\
\hline Apply or not & 0.005 & 0.07 & 97,512 & $40.37 \%$ \\
\hline Questionnaire complete or not & 0.004 & 0.06 & 97,512 & $40.37 \%$ \\
\hline Generic wage expectation midpoint & 9763.91 & 7648.50 & 80,377 & $39.96 \%$ \\
\hline Current/most recent job wage midpoint & 8233.80 & 7143.59 & 92,828 & $39.89 \%$ \\
\hline Female & 0.58 & 0.49 & 97,512 & $40.37 \%$ \\
\hline Married & 0.58 & 0.49 & 58,612 & $0.79 \%$ \\
\hline Age & 27.97 & 4.67 & 97,512 & $40.37 \%$ \\
\hline Age $^{2}$ & 803.99 & 293.90 & 97,512 & $40.37 \%$ \\
\hline Beijing Hukou & 0.28 & 0.45 & 97,162 & $40.15 \%$ \\
\hline \multicolumn{5}{|l|}{ Educational degree } \\
\hline College & 0.30 & 0.46 & 97,512 & $40.37 \%$ \\
\hline Bachelor & 0.59 & 0.49 & 97,512 & $40.37 \%$ \\
\hline Master or above & 0.11 & 0.32 & 97,512 & $40.37 \%$ \\
\hline \multicolumn{5}{|l|}{ Work experience } \\
\hline Experience & 5.69 & 4.43 & 97,512 & $40.37 \%$ \\
\hline Experience $^{2}$ & 52.01 & 91.36 & 97,512 & $40.37 \%$ \\
\hline Overseas studying or work experience & 0.05 & 0.23 & 97,512 & $40.37 \%$ \\
\hline \multicolumn{5}{|l|}{ Employment status } \\
\hline Currently employed & 0.38 & 0.49 & 96,725 & $39.88 \%$ \\
\hline Tenure & 1.14 & 2.28 & 96,725 & $39.88 \%$ \\
\hline Tenure $^{2}$ & 6.50 & 27.61 & 96,725 & $39.88 \%$ \\
\hline \multicolumn{5}{|l|}{ Job expectation } \\
\hline Expect to work full time & 0.97 & 0.17 & 97,458 & $40.33 \%$ \\
\hline Expect to work part time & 0.01 & 0.11 & 97,458 & $40.33 \%$ \\
\hline Expect to work as an intern & 0.02 & 0.13 & 97,458 & $40.33 \%$ \\
\hline Expect to work in Beijing & 0.90 & 0.29 & 97,362 & $40.27 \%$ \\
\hline \multicolumn{5}{|l|}{ Wage offer ranges } \\
\hline High & 0.33 & 0.47 & 97,512 & $40.37 \%$ \\
\hline Medium & 0.33 & 0.47 & 97,512 & $40.37 \%$ \\
\hline Low & 0.33 & 0.47 & 97,512 & $40.37 \%$ \\
\hline \multicolumn{5}{|l|}{ Job flexibility conditions } \\
\hline NoFlex & 0.24 & 0.43 & 97,512 & $40.37 \%$ \\
\hline TimeFlex & 0.27 & 0.44 & 97,512 & $40.37 \%$ \\
\hline PlaceFlex & 0.23 & 0.42 & 97,512 & $40.37 \%$ \\
\hline FullFlex & 0.26 & 0.44 & 97,512 & $40.37 \%$ \\
\hline \multicolumn{5}{|l|}{ Job positions } \\
\hline Java & 0.17 & 0.37 & 97,512 & $40.37 \%$ \\
\hline Finance & 0.21 & 0.40 & 97,512 & $40.37 \%$ \\
\hline HR & 0.28 & 0.45 & 97,512 & $40.37 \%$ \\
\hline Marketing & 0.20 & 0.40 & 97,512 & $40.37 \%$ \\
\hline Sales & 0.14 & 0.35 & 97,512 & $40.37 \%$ \\
\hline
\end{tabular}

Notes: After dropping observations with missing data, inconsistent dates of events, and applications to jobs in different flexibility conditions or job positions from those they were sent in the job ad emails and app messages, the sample available for the regression analysis including all of these variables has $\mathrm{N}=58,151$ (from a total sample of 97,512 observations). 


\section{Appendix Table E4. Random search vs. directed search conditional on RW no more than 15,000 CNY, using generic wage expectation as RW proxy}

\begin{tabular}{|c|c|c|c|c|}
\hline \multirow{2}{*}{$\begin{array}{l}\text { Sample restriction } \\
\text { Dependent variable }\end{array}$} & \multicolumn{2}{|c|}{ Less restrictive } & \multicolumn{2}{|c|}{ More restrictive } \\
\hline & $\begin{array}{l}\text { Apply or not } \\
\text { (1) }\end{array}$ & $\begin{array}{c}\text { Complete or not } \\
\left(1^{\prime}\right)\end{array}$ & $\begin{array}{c}\text { Apply or not } \\
(2)\end{array}$ & $\begin{array}{l}\text { Complete or not } \\
\left(2^{\prime}\right)\end{array}$ \\
\hline $\begin{array}{l}\text { Average application/ questionnaire } \\
\text { completion rate for Low }\end{array}$ & $0.34 \mathrm{ppt}$ & $0.22 \mathrm{ppt}$ & & \\
\hline $\begin{array}{l}\text { Percentage increase for Medium } \\
\text { relative to Low average }\end{array}$ & $-4.09 \%$ & $-3.49 \%$ & & \\
\hline $\begin{array}{l}\text { Percentage increase for High } \\
\text { relative to Low average }\end{array}$ & $17.94 \%$ & $23.60 \%$ & & \\
\hline $\begin{array}{l}\text { Average application/ questionnaire } \\
\text { completion rate for Medium }\end{array}$ & $0.35 p p t$ & $0.22 \mathrm{ppt}$ & $0.35 p p t$ & $0.22 \mathrm{ppt}$ \\
\hline $\begin{array}{l}\text { Percentage increase for High } \\
\text { relative to Medium average }\end{array}$ & $21.55 \%^{\dagger}$ & $27.05 \%^{\dagger}$ & $16.74 \%$ & $21.28 \%$ \\
\hline Medium & $\begin{array}{l}-0.0001 \\
(0.0004)\end{array}$ & $\begin{array}{l}-0.0001 \\
(0.0003)\end{array}$ & & \\
\hline High & $\begin{array}{l}0.0006^{\dagger} \\
(0.0004)\end{array}$ & $\begin{array}{l}0.0005^{\dagger} \\
(0.0003)\end{array}$ & $\begin{array}{c}0.0006 \\
(0.0004)\end{array}$ & $\begin{array}{c}0.0005 \\
(0.0003)\end{array}$ \\
\hline Job characteristics & Yes & Yes & Yes & Yes \\
\hline Job seeker characteristics & Yes & Yes & Yes & Yes \\
\hline Number of job seekers & 41,693 & 41,693 & 27,792 & 27,792 \\
\hline
\end{tabular}

Notes: See notes to Table 3. The only difference is the RW measure used, i.e., generic wage expectation. 


\section{Appendix F. Robustness checks to sample selection/data availability}

One question is whether the sample selection rules based on data availability and other issues might bias the results. In this appendix, we provide information that this is not the case, showing that the regression results are robust in six different samples defined by the conditions regarding data on RWs and job seeker characteristics.

Appendix Table F1 reports the regression results for our key specifications (from Tables 2 and 3) for the outcomes of applying or completing the questionnaire (Panels A and B). The sample selection conditions are indicated in column headings. Specifically, these differ by whether the RW is considered (i.e., irrespective of whether RW is disclosed), disclosed, and disclosed and $\leq 15,000$ CNY, and whether job seeker characteristics are non-missing. The sample size in columns (2) and (3) becomes $95.2 \%$ and $83.1 \%$ of that in column (1), respectively. Columns (1), (7) and (9) reproduce results from Tables 2 and 3 in the paper, as indicated in the "Corresponding results in paper” row. Comparing the results across the columns shows that the results are qualitatively similar regardless of the sample selection.

In addition, the table shows that RWs are not more likely to be disclosed by those who apply than those who do not apply. Specifically, in column (1), the number of applicants is 328. The percentages of applicants (non-applicants) who disclose RWs in columns (2) and (3) are 99.1\% (95.2\%) and 76.2\% (83.1\%), relative to column (1). The percentages of applicants (non-applicants) who reveal RWs in columns (5) and (6) are 99.3\% (95.9\%) and 76.5\% (87.1\%), relative to column (1). Thus, the percentages for applicants are greater than those for non-applicants in columns (2) and (5) but larger in columns (3) and (6) samples; i.e., applicants are not consistently more likely or less likely to disclose RWs than non-applicants. The evidence for questionnaire completers and non-completers (Panel B) is very similar. 
Appendix Table F1. Regression results for each sample

\begin{tabular}{|c|c|c|c|c|c|c|c|c|c|}
\hline Sampling condition: RW & $\begin{array}{l}\text { Not considering } \\
\text { RW }\end{array}$ & $\begin{array}{c}\text { RW } \\
\text { disclosed }\end{array}$ & $\begin{array}{c}\text { RW disclosed \& } \\
\text { RW } \leq \\
15,000 \mathrm{CNY}\end{array}$ & $\begin{array}{l}\text { Not considering } \\
\text { RW }\end{array}$ & RW disclosed & $\begin{array}{c}\text { RW disclosed } \\
\& \mathrm{RW} \leq \\
15,000 \mathrm{CNY}\end{array}$ & $\begin{array}{c}\text { Not } \\
\text { considering } \\
\text { RW }\end{array}$ & RW disclosed & $\begin{array}{c}\text { RW disclosed \& } \\
\text { RW } \leq \\
15,000 \mathrm{CNY}\end{array}$ \\
\hline $\begin{array}{l}\text { Sampling condition: Job seeker } \\
\text { characteristics non-missing }\end{array}$ & No & No & No & Yes & Yes & Yes & Yes & Yes & \\
\hline \multicolumn{7}{|c|}{ Panel A. Dependent variable: Apply or not } & & & \\
\hline Corresponding results in paper & Table 2 col. (2) & & & & & & Table 2 col. (3) & & Table 3 col. (1) \\
\hline & $(1)$ & (2) & (3) & (4) & (5) & (6) & $(7)$ & (8) & (9) \\
\hline Average application rate for Low & $0.27 \%$ & $0.28 \%$ & $0.28 \%$ & $0.41 \%$ & $0.42 \%$ & $0.40 \%$ & $0.41 \%$ & $0.42 \%$ & $0.40 \%$ \\
\hline $\begin{array}{l}\text { Percentage increase for Medium } \\
\text { relative to Low average }\end{array}$ & $11.70 \%$ & $13.20 \%$ & $1.03 \%$ & $25.21 \%$ & $25.78 \%^{*}$ & $11.62 \%$ & $11.40 \%$ & $11.52 \%$ & $3.69 \%$ \\
\hline $\begin{array}{l}\text { Percentage increase for High relative } \\
\text { to Low average }\end{array}$ & $42.75 \% \%^{* * *}$ & $42.65 \%{ }^{* * *}$ & $21.46 \%$ & $55.79 \% * *$ & $54.27 \%$ *** & $33.82 \%{ }^{* *}$ & $38.32 \%{ }^{* * *}$ & $37.31 \%^{* * *}$ & $24.90 \%{ }^{* *}$ \\
\hline Average application rate for Medium & $0.31 \%$ & $0.33 \%$ & $0.28 \%$ & $0.52 \%$ & $0.54 \%$ & $0.45 \%$ & $0.52 \%$ & $0.54 \%$ & $0.45 \%$ \\
\hline $\begin{array}{l}\text { Percentage increase for High relative } \\
\text { to Medium average }\end{array}$ & $27.14 \%^{\dagger \dagger}$ & $25.40 \%^{\dagger}$ & $19.91 \%$ & $23.83 \%^{\dagger+}$ & $22.15 \%$ & $19.48 \%$ & $20.97 \%^{\dagger \dagger}$ & $20.05 \%{ }^{\dagger+}$ & $18.61 \%^{\dagger}$ \\
\hline Medium & $\begin{array}{c}0.0003 \\
(0.0004)\end{array}$ & $\begin{array}{c}0.0004 \\
(0.0004)\end{array}$ & $\begin{array}{l}0.00003 \\
(0.0004)\end{array}$ & $\begin{array}{c}0.0010 \\
(0.0006)\end{array}$ & $\begin{array}{l}0.0011^{*} \\
(0.0007)\end{array}$ & $\begin{array}{c}0.0005 \\
(0.0006)\end{array}$ & $\begin{array}{c}0.0005 \\
(0.0004)\end{array}$ & $\begin{array}{c}0.0005 \\
(0.0004)\end{array}$ & $\begin{array}{c}0.0001 \\
(0.0004)\end{array}$ \\
\hline High & $\begin{array}{c}0.0012^{* * *,+\dagger} \\
(0.0004)\end{array}$ & $\begin{array}{c}0.0012^{* * *}, \dagger \\
(0.0004)\end{array}$ & $\begin{array}{l}0.0006 \\
(0.0004)\end{array}$ & $\begin{array}{c}0.0023^{* * *, \dagger}+ \\
(0.0007)\end{array}$ & $\begin{array}{l}0.0023^{* * *} \\
(0.0007)\end{array}$ & $\begin{array}{l}0.0013^{* *} \\
(0.0007)\end{array}$ & $\begin{array}{c}0.0016^{* * *,+\dagger} \\
(0.0004)\end{array}$ & $\begin{array}{l}0.0016^{* * *,+\dagger} \\
(0.0005)\end{array}$ & $\begin{array}{l}0.0010^{* *, \dagger} \\
(0.0005)\end{array}$ \\
\hline $\begin{array}{l}\text { Job characteristics } \\
\text { Job seeker characteristics }\end{array}$ & $\begin{array}{l}\text { Yes } \\
\text { No }\end{array}$ & $\begin{array}{l}\text { Yes } \\
\text { No }\end{array}$ & $\begin{array}{l}\text { Yes } \\
\text { No }\end{array}$ & $\begin{array}{l}\text { Yes } \\
\text { No }\end{array}$ & $\begin{array}{l}\text { Yes } \\
\text { No }\end{array}$ & $\begin{array}{l}\text { Yes } \\
\text { No }\end{array}$ & $\begin{array}{l}\text { Yes } \\
\text { Yes }\end{array}$ & $\begin{array}{l}\text { Yes } \\
\text { Yes }\end{array}$ & $\begin{array}{l}\text { Yes } \\
\text { Yes }\end{array}$ \\
\hline Number of job seekers & 99,146 & 94,377 & 82,364 & 58,151 & 55,799 & 50,641 & 58,151 & 55,799 & 50,641 \\
\hline Number of applicants & 328 & 325 & 250 & 307 & 305 & 235 & 307 & 305 & 235 \\
\hline \multicolumn{7}{|c|}{$\begin{array}{l}\text { Panel B. Dependent variable: Complete or not } \\
\text { Corresponding results in paper }\end{array}$} & Table 2 col. (3’) & & Table 3 col. (1') \\
\hline $\begin{array}{l}\text { Average questionnaire completion } \\
\text { rate for Low }\end{array}$ & $0.16 \%$ & $0.17 \%$ & $0.17 \%$ & $0.25 \%$ & $0.26 \%$ & $0.25 \%$ & $0.25 \%$ & $0.26 \%$ & $0.25 \%$ \\
\hline $\begin{array}{l}\text { Percentage increase for Medium } \\
\text { relative to Low average }\end{array}$ & $26.21 \%$ & $28.91 \%$ & $11.56 \%$ & $39.11 \%{ }^{*}$ & $39.87 \%{ }^{* *}$ & $20.94 \%$ & $20.69 \%^{*}$ & $20.79 \%^{*}$ & $10.65 \%$ \\
\hline $\begin{array}{l}\text { Percentage increase for High relative } \\
\text { to Low average }\end{array}$ & $60.98 \% \%^{* * *}$ & $62.64 \%{ }^{* * *}$ & $37.57 \%^{*}$ & $76.17 \%^{* * *}$ & $75.24 \%{ }^{* * *}$ & $49.61 \%{ }^{* *}$ & $53.55 \%{ }^{* * *}$ & $52.65 \%{ }^{* * *}$ & $36.37 \%{ }^{* *}$ \\
\hline $\begin{array}{l}\text { Average questionnaire completion } \\
\text { rate for Medium }\end{array}$ & $0.21 \%$ & $0.22 \%$ & $0.19 \%$ & $0.36 \%$ & $0.37 \%$ & $0.31 \%$ & $0.36 \%$ & $0.37 \%$ & $0.31 \%$ \\
\hline $\begin{array}{l}\text { Percentage increase for High relative } \\
\text { to Medium average }\end{array}$ & $26.33 \%^{\dagger}$ & $25.02 \%$ & $22.58 \%$ & $25.69 \%$ & $24.46 \%$ & $23.05 \%$ & $22.78 \%^{\dagger \dagger}$ & $22.03 \%{ }^{\dagger \dagger}$ & $20.67 \%^{\dagger}$ \\
\hline Medium & $\begin{array}{c}0.0004 \\
(0.0003)\end{array}$ & $\begin{array}{c}0.0005 \\
(0.0003)\end{array}$ & $\begin{array}{c}0.0002 \\
(0.0003)\end{array}$ & $\begin{array}{l}0.0010^{*} \\
(0.0005)\end{array}$ & $\begin{array}{l}0.0010^{* *} \\
(0.0005)\end{array}$ & $\begin{array}{c}0.0005 \\
(0.0005)\end{array}$ & $\begin{array}{c}0.0005^{*} \\
(0.0003)\end{array}$ & $\begin{array}{c}0.0005^{*} \\
(0.0003)\end{array}$ & $\begin{array}{c}0.0003 \\
(0.0003)\end{array}$ \\
\hline High & $\begin{array}{c}0.0010^{* * *, \dagger} \\
(0.0003)\end{array}$ & $\begin{array}{l}0.0010^{* * * *} \\
(0.0003)\end{array}$ & $\begin{array}{l}0.0006^{*} \\
(0.0003)\end{array}$ & $\begin{array}{l}0.0019^{* * *} \\
(0.0005)\end{array}$ & $\begin{array}{l}0.0019^{* * * *} \\
(0.0006)\end{array}$ & $\begin{array}{l}0.0012^{* *} \\
(0.0006)\end{array}$ & $\begin{array}{c}0.0013^{* * *,+\dagger} \\
(0.0004)\end{array}$ & $\begin{array}{l}0.0014^{* * *,+\dagger} \\
(0.0004)\end{array}$ & $\begin{array}{l}0.0009^{* *, \dagger} \\
(0.0004)\end{array}$ \\
\hline Job characteristics & Yes & Yes & Yes & Yes & Yes & Yes & Yes & Yes & Yes \\
\hline Job seeker characteristics & No & No & No & No & No & No & Yes & Yes & Yes \\
\hline Number of job seekers & 99,146 & 94,377 & 82,364 & 58,151 & 55,799 & 50,641 & 58,151 & 55,799 & 50,641 \\
\hline Number of questionnaire completers & 214 & 212 & 166 & 205 & 204 & 159 & 205 & 204 & 159 \\
\hline
\end{tabular}

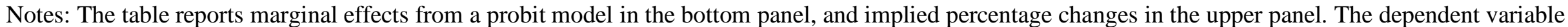

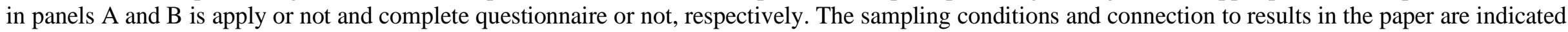
in column headings. See also notes to Table 2. 


\section{Appendix G. The RW-age profile}

We estimate the RW-age profile from regressions of RWs on age, controlling for the same job seeker characteristics as in Table 2 of the paper. (The only difference is that we drop work experience, since the prediction that updating of RWs implies a positive RW-age profile is based on age as a proxy for experience, rather than conditional on experience.) We do this for the sample of job seekers that have non-missing and consistent characteristics and non-missing values for the RW. Appendix Table G1 reports the results, first with just a linear age term and then adding age squared. Column (1), with the linear term only, shows a significant and positive relationship between RW and age. Column (2) shows a concave relationship between RW and age; the implied effect of age is positive at ages below 81, which covers the entire sample. Therefore, the evidence points to a positively-sloped RW-age profile, consistent with RWs being updated.

\begin{tabular}{lcc}
\multicolumn{4}{l}{ Appendix Table G1. Regression result for RW-age profile } \\
\hline Dependent variable: RW & $(1)$ & $(2)$ \\
\hline Age & $533.6782^{* * *}$ & $866.9206^{* * *}$ \\
\multirow{2}{*}{ Age $^{2}$} & $(10.0794)$ & $(76.9522)$ \\
& & $-5.3324^{* * *}$ \\
\hline Observations $^{\text {Ond }}$ & & $(1.3169)$ \\
\hline
\end{tabular}

Notes: The RW is measured by the current/most recent job's wage. The sample includes only job seekers who were sent job ad emails and app messages, have non-missing and consistent characteristics, and have non-missing values for RW. All models include control variables for job seeker characteristics as in columns (3) and (3') of Table 2, except we drop work experience. When we include age squared, we also include the quadratic tenure term. ${ }^{* * *}$ indicate statistical significance at the $1 \%$ level. 